\title{
Cellular and Subcellular Localization of NMDA-R1 Subunit Immunoreactivity in the Visual Cortex of Adult and Neonatal Rats
}

\author{
Chiye Aoki, ${ }^{1,2}$ Charu Venkatesan, ${ }^{1}$ C.-G. Go, ${ }^{1}$ Jessica A. Mong, ${ }^{3}$ and Ted M. Dawson ${ }^{3}$

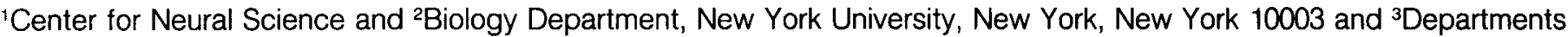 \\ of Neurology and Neuroscience, The Johns Hopkins University School of Medicine, Baltimore, Maryland 21205
}

NMDA receptor activation can alter synaptic strength, cause cell death, and may modulate the release of glutamate and other neurotransmitters. Using a specific and selective antiserum directed against the $R 1$ subunit of the NMDA receptor, we examined (1) whether NMDA receptors in the adult rat visual cortex are exclusively postsynaptic or also presynaptic and (2) whether NMDA-R1 subunits are incorporated into the plasma membrane prior to, contemporaneously, or following the formation of synapses during postnatal development. By light microscopy, NMDA-R1 immunoreactivity in the adult visual cortex is easily detectable within perikarya and proximal dendrites in laminae 2-6. Many of them have the morphological features of pyramidal neurons. In addition, fine punctate labeling is evident throughout the neuropil. Electron microscopy reveals these puncta to reside at postsynaptic densities of axospinous junctions and at fine astrocytic processes and axon terminals. In the deeper laminae, the majority of labeled profiles are astrocytic. Visual cortices of animals in their first postnatal week show concentrated immunoreactivity in a few nonpyramidal neurons within laminae that have just differentiated from the cortical plate. Electron microscopy reveals diffuse labeling along the plasma membrane of dendritic shatts lacking morphologically identifiable synaptic junctions or appositions to axons. Immunoreactivity is detectable in dendritic processes by postnatal day (PND) 2, in axonal processes by PND 4, and in astrocytic profiles by PND 14. Immunoreactivity also is detectable along the postsynaptic membrane of presumably transient axosomatic junctions. At all ages, the prevalence of NMDA-R1-immunoreactive profiles is lamina $1>4 / 5>$ $6 / 6 \mathrm{~B}$. These results provide the cellular basis for NMDA receptors' participation in (1) postsynaptic membrane excitability, (2) regulation of transmitter release, (3) and, in the deeper laminae, astrocyte responses. During development, NMDA-R1 subunits are associated with the plasma membrane prior to axons' arrival while clustering of receptors to

\footnotetext{
Received Dec. 7, 1993; revised Feb. 15, 1994; accepted Feb. 24, 1994

This work was funded by the following grants to C.A.: NIH-NINDS NS30944, NIH-NEI R29-EY08055 (FIRST Award), NSF RCD92-53750 (Presidential Faculty Fellowship), and Human Frontiers Science Program Award RG-16/93. T.M.D. is supported by grants from the American Academy of Neurology and the Public Health Service CIDA NS-01578. We thank Dr. A. S. Sharp and M. Fotuhi for their expert advice during preparation of the antibody, and Demitrios Galifianakis and Byron Taylor for their technical assistance. We thank Dr. S. Nakanishi for the gift of NMDA-R1 cDNA. We also thank Dr. Wu-Schyong Liu, Department of Biological Chemistry, Johns Hopkins University, for synthesis of the peptide.

Correspondence should be addressed to Chiye Aoki, Center for Neural Science, 6 Washington Place, New York, NY 10003

Copyright $\odot 1994$ Society for Neuroscience $0270-6474 / 94 / 145202-21 \$ 05.00 / 0$
}

junctions may be promoted by axonal contact. Finally, spatial segregation of axonal growth cones may be mediated by NMDA-R 1 subunits on these axonal processes.

[Key words: NMDA, glutamate, receptor localization, postsynaptic density, synapse, heteroreceptor, autoreceptor, astrocyte, presynaptic]

In the cerebral cortex, L-glutamate mediates thalamocortical, corticocortical, and corticofugal neurotransmission (reviewed by Streit, 1984). In adulthood, thalamocortical synapses activate primarily non-NMDA receptors, while the other two pathways utilize a mixture of NMDA and non-NMDA receptors (Thomson, 1986; Hagihara et al., 1988; Shirokawa et al., 1989; Nishigori et al., 1990; Tsumoto, 1990). Electrophysiological analyses indicate that NMDA-sensitive synapses in the visual cortex occur throughout the laminae during early postnatal periods: however, only those visually evoked responses in the superficial laminae retain NMDA sensitivity through adulthood (Fox et al., 1989). Fox et al. (1991) also suggest that NMDA receptors in the deeper laminae are downregulated by an activity-dependent mechanism, since cats reared in the dark from birth continue to exhibit NMDA-sensitive receptors in laminae 4-6. Since dark-rearing extends the critical period for plasticity as well (Cynader and Mitchell, 1980), developmental plasticity may depend on the presence of NMDA receptors at nascent synapses, while loss of plasticity may be accompanied by activity-dependent pruning of NMDA receptors within specific laminae. Supporting the notion that NMDA receptors play important roles in developmental plasticity, NMDA receptor antagonists disrupt experience-dependent modification of cortical synapses during development (Kleinschmidt et al., 1987; Bear et al., 1990; reviewed by Fox and Daw, 1993).

In the present study, we determined whether the formation of morphologically identifiable synaptic specialization in the visual cortex precedes or follows the clustered localization of NMDA receptors along the plasma membrane. We chose to use an anti-NMDA-R 1 antibody because the NMDA-R 1 is a subunit of the heteromeric NMDA receptor (Kutsuwada et al., 1992; Meguro et al., 1992; Monyer et al., 1992) with ubiquitous distribution within brain (Moriyoshi et al., 1992). To this end, we produced a polyclonal rabbit antibody directed against a C-terminal peptide of the NMDA-R1 subunit to characterize the subcellular distribution of NMDA-R 1 immunoreactivity in relation to synaptic junctions within the superficial, middle, and decper laminac of developing rat visual cortices.

Our second objective was to determine whether NMDA receptors reside exclusively postsynaptically or whether they may also reside presynaptically. Almost all of the electrophysiolog- 
ical studies point to the function of postsynaptic NMDA receptors (reviewed by Ascher and Nowak, 1987; MacDermott and Dale, 1987). However, presynaptic NMDA receptors may regulate the release of L-glutamate and other transmitters (Moghaddam et al., 1990; Krebs et al., 1991; Martin et al., 1991; Bustos et al., 1992; Lehmann et al., 1992; Wang et al., 1992). The existence of presynaptic NMDA remains controversial, since transmitter release may be enhanced by nitric oxide (NO) that is postsynaptic in origin, released upon activation of postsynaptic NMDA receptors, and retrograde in its action (Hanbauer et al., 1992; Hirsch et al., 1993; reviewed by Dawson and Snyder, 1993). Furthermore, NMDA receptors may reside on some axons, at least during development, since NMDA receptor antagonists can prevent axonal segregation of retinogeniculate axons in the developing cat lateral geniculate nucleus (Hahm et al., 1991) and of the retinotectal axons in the frog tectum (Cline et al., 1987). Thus, immunoelectron microscopy was used to determine the pre- versus postsynaptic localization of the receptor in the visual cortex of adult and neonatal rat visual cortex.

\section{Materials and Methods}

\section{Preparation of anti-NMDA-R1 antiserum}

A synthetic peptide based on the C-terminal amino acids (923-938; KEREEGQLQLCSRHRES) of the NMDA-R1 protein (Moriyoshi et al., 1991) was made and conjugated to bovine serum albumin (BSA). A lysine was synthesized on the $\mathrm{N}$-terminus of the peptide to facilitate coupling. BSA was added to the peptide at a ratio of approximately one BSA molecule per 10 peptide molecules, followed by addition of glutaraldehyde (final concentration, $0.1 \%$ ). After incubation of the three reagents for $1 \mathrm{hr}$ at room temperature, the conjugation reaction was stopped by incubation with excess glycine for $1 \mathrm{hr}$ at room temperature. The conjugate was dialyzed first against $100 \mathrm{~mm}$ sodium acetate, $\mathrm{pH}$ 4.2 , for $5 \mathrm{hr}$ and then against phosphate-buffered saline (PBS) overnight. Antisera were raised in rabbits injected with the above BSA-conjugated peptide (Cocalico Biologicals, Inc., Reamstown, PA).

Antiserum was purified at two steps. First it was adsorbed overnight, at $4^{\circ} \mathrm{C}$, with an affinity matrix consisting of proteins extracted from crude brain membrane using high $\mathrm{pH}(\mathrm{NaOH}$ extract) and immobilized on cyanogen bromide (CNBr)-activated Sepharose. Finally, it was affinity purified using a column consisting of an ovalbumin-NMDA-R 1 peptide conjugate immobilized on C.NBr-activated Sepharose, batchwise, overnight at $4^{\circ} \mathrm{C}$. The antiserum was eluted from the column with $4 \mathrm{M} \mathrm{MgCl}_{2}$, dialyzed against PBS and then against PBS containing $20 \%$ sucrose, and stored in small aliquots at $-70^{\circ} \mathrm{C}$ until use.

\section{Western blot analysis of antiserum specificity}

COS-7 cells maintained in Dulbecco's modified Eagle's medium with $10 \%$ fetal calf serum were transfected by electroporation with $20 \mu \mathrm{g}$ of the cDNA for the NMDA-R 1 subunit (provided by S. Nakanishi) per $150 \mathrm{~cm}^{2}$ tissue culture flask. Control extracts were prepared from cells transfected with $20 \mu \mathrm{g}$ of pcDNA. Cells were harvested $2 \mathrm{~d}$ after transfection by scraping in $2 \mathrm{ml}$ of $50 \mathrm{~mm}$ Tris- $\mathrm{HCl}, \mathrm{pH} \mathrm{7.4,} \mathrm{containing} 1$ mM EDTA, $0.5 \mathrm{~mm}$ phenylmethylsulfonyl fluoride, $4.8 \mu \mathrm{g} / \mathrm{ml}$ antipain, $9.6 \mathrm{mg} / \mathrm{ml}$ leupeptin, $9.6 \mathrm{mg} / \mathrm{ml}$ aprotinin, $5 \mu \mathrm{g} / \mathrm{ml}$ chymostatin, $5 \mu \mathrm{g} /$ $\mathrm{ml}$ pepstatin $\mathrm{A}$, and $1 \mathrm{~mm}$ benzamidine, and then homogenized.

For immunoblot analysis, particulate fractions were prepared from different brain regions in $50 \mathrm{~mm}$ Tris- $\mathrm{HCl}, \mathrm{pH} \mathrm{7.4,} \mathrm{containing} 1 \mathrm{~mm}$ EDTA, $0.5 \mathrm{~mm}$ phenylmethylsulfonyl fluoride, $4.8 \mu \mathrm{g} / \mathrm{ml}$ antipain, 9.6 $\mathrm{mg} / \mathrm{ml}$ leupeptin, $9.6 \mathrm{mg} / \mathrm{ml}$ aprotinin, $5 \mu \mathrm{g} / \mathrm{ml}$ chymostatin, $5 \mu \mathrm{g} / \mathrm{ml}$ pepstatin $A$, and $1 \mathrm{~mm}$ benzamidine, and transfected $C O S$ cell extracts as described. Proteins ( $20 \mu \mathrm{g}$ per lane of COS-7 cell extract and $150 \mu \mathrm{g}$ per lane of tissue extract) were size fractionated on $3.5-17 \%$ gradient gels, transferred to Immobilon-P membrane (Millipore), and probed with affinity-purified antibody $(1: 1000)$ overnight at $4^{\circ} \mathrm{C}$. Blots were then washed and incubated with alkaline phosphatase-linked goat antirabbit secondary antibody (1:2000; Boehringer Mannheim) for $90 \mathrm{~min}$ at room temperature. Bands were visualized with nitroblue tetrazolium and 5-bromo-4-chloro-3-indoyl phosphate. For preadsorption experiments performed on COS cell extracts and different brain regions, an- tibodies was preincubated with 20 -fold excess of peptide antigen for 24 hr at $4^{\circ} \mathrm{C}$

\section{Immunocytochemistry}

Source of tissue. Six adult rats and three litters of neonatal rats $(n=29)$ were used. The age of the neonatal rats ranged from postnatal day (PND) 2 to 30 (PND $0=$ birthday), at which time ultrastructural features are reported to be indistinguishable from those of adults (Parnavelas and Blue, 1983a). Ten were killed at PND 2-4, six at PND 6-7, six at PND 9-10, four at PND 14, two at PND 18, and one at PND 30. All rats were anesthetized using Nembutal. They were perfused through the ascending aorta or left ventricle with the following solutions using a peristaltic pump: (1) heparinized saline, buffered to $\mathrm{pH} 7.4$ using 0.01 M phosphate buffer for about $1 \mathrm{~min}$; then (2) $50 \mathrm{ml}$ of an aldehyde mixture consisting of $3 \%$ acrolein and $2 \%$ freshly prepared paraformaldehyde, buffered to $\mathrm{pH} 7.4$ using $0.1 \mathrm{M}$ phosphate buffer (PB); followed by (3) $2 \%$ paraformaldehyde in PB for a 6 min period. Alternatively, perfusates 2 and 3 were replaced by an aldehyde solution consisting of $4 \%$ paraformaldehyde alone, buffered with PB. Adults were perfused at a rate of $70 \mathrm{ml} / \mathrm{min}$. Neonates were perfused at a slower ratc, ranging from 15 to $50 \mathrm{ml} / \mathrm{min}$. Carc was taken to maintain the perfusion rate below the level that would rupture intranasal capillaries. Adult rat brains were sectioned $30 \mathrm{~min}$ following perfusion using a vibratome at a thickness of $40 \mu \mathrm{m}$. Neonatal brains were postfixed overnight at $4^{\circ} \mathrm{C}$ in perfusate 3 , and then sectioned at a thickness ranging from 60 to $100 \mu \mathrm{m}$ using a vibratome. Sections fixed with acrolein were immersed in a solution containing $1 \%$ sodium borohydride in $\mathrm{PB}$ to terminate further cross-linking of proteins (King et al., 1983). After rinsing in $\mathrm{PB}$, these sections were rinsed in $0.1 \mathrm{M}$ Tris-buffered saline (TBS) adjusted to $\mathrm{pH} 7.6$ using $\mathrm{HCl}$.

Light microscopic immunocytochemistry. Light microscopic visualization of immunoreactivity was achieved by the avidin-biotin-peroxidase complex method of Hsu et al. (1981) as detailed previously (Chan et al., 1990) using a commercial source of the complex (Vector Labs). In pilot experiments, the antiserum's final dilution ranged from 1:1000 to $1: 5000(1-0.2 \mu \mathrm{g} \mathrm{IgG/ml})$. Subsequently, an overnight incubation with antiserum at a dilution of 1:5000 was performed for all neonatal and adult tissues.

Electron microscopic immunocytochemistry. Sections processed for immunocytochemistry were then postfixed to achieve sufficient preservation of the membranes for electron microscopy. Those sections fixed with $4 \%$ paraformaldehyde were postfixed by immersing them for 10 min in $2 \%$ glutaraldehyde buffered with PBS. Fixation was terminated by rinsing sections in PBS. Previous studies had indicated that sections fixed with acrolein did not require postfixation with glutaraldehyde. All sections were further postfixed with $2 \%$ osmium tetroxide/ $0.1 \mathrm{M} \mathrm{PB}$ for $1 \mathrm{hr}$, and then rinsed in $\mathrm{PB}$. They were processed for electron microscopy as described earlier (Chan et al., 1990). Care was taken to construct mesa that spanned all of the layers of the visual cortex. This was possible because the capsule-embedded vibratome sections could be examined under a light microscope to identify laminar features. Approximately 50 ultrathin sections, $70-90 \mathrm{~nm}$ thick, were collected from surfacemost portions of the vibratome sections, and then counterstained using uranyl acetate and lead citrate. These sections were examined using a JEOL $1200 \mathrm{XL}$ electron microscope.

Control experiments. Specificity of immunocytochemical labeling was assessed by running parallel staining procedures in which (1) the primary antiserum was omitted from the incubation buffer, (2) the primary antiserum dilution was substituted by a preadsorbed antiserum, and (3) inappropriate secondary antibodies (e.g., anti-mouse IgG rather than anti-rabbit IgG) were used.

\section{Semiquantitative analysis of ultrathin sections}

Analysis was performed to determine the areal density of (1) immunolabeled somatic, dendritic, axonal, and astrocytic profiles and (2) immunolabeled and unlabeled synapses per $100 \mu \mathrm{m}^{2}$ of neuropil area in laminae $1,4 / 5$, and $6-6 \mathrm{~B}$ at various ages. The analysis was performed strictly from portions of the ultrathin sections exhibiting tissue-Epon interface. Laminae 1 and $6 \mathrm{~B}$ were identified within the ultrathin sections by using pial surface and white matter as landmarks. The cortical plate could be identified easily by the high packing density of perikarya. Using grid mesh as tick marks for estimating distance, the "middle layers" corresponding to intensely immunolabeled laminae, 4 and 5 (referred to as the "subplate" by Rice and Van der Loos, 1977, but not by Rakic, 


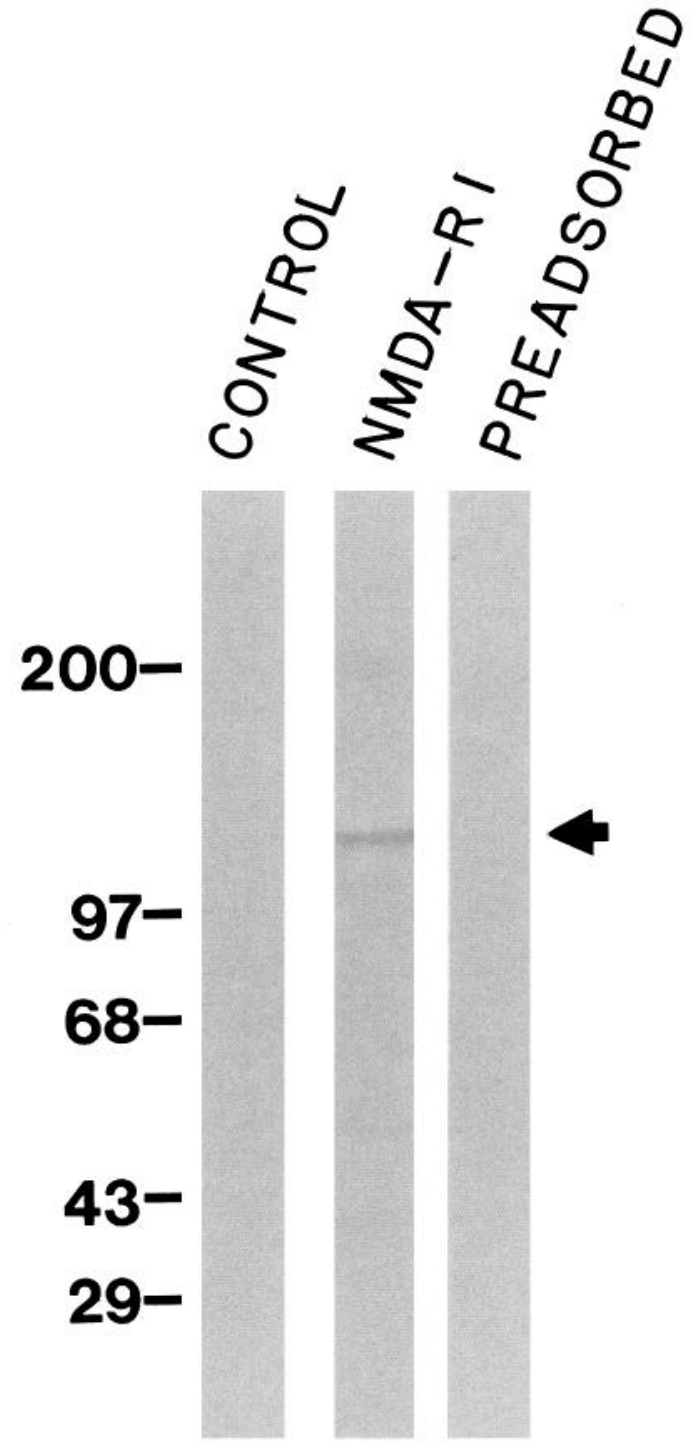

Figure 1. Specificity of the anti-NMDA-R1 antibody as revealed by Western blot analysis. The anti-NMDA-R 1 antibody (1:1000) recognizes a single band of molecular weight $\sim 110 \mathrm{kDa}$ (arrow) within a COS-7 membrane preparation transfected with the NMDA-R1 gene (NMDA-R1 lane). Western blot of a nontransfected COS-7 cell incubated in an identical dilution of the antibody shows no immunoreactivity (CONTROL lane). Western blot of a COS-transfected membrane preparation incubated with the same dilution of the antibody but preadsorbed with excess shows no immunoreactivity (PREADSORBED lane).

1977, or by Luskin and Shatz, 1985), were identified by relating their distances from pial and white matter as seen under light and electron microscopes. The areal density of profiles was determined by tabulating their frequency within a grid's square $\left(\right.$ area $\left.\sim 2500 \mu \mathrm{m}^{2}\right)$. Then, a lowmagnification micrograph of the analyzed mesh square area was taken so as to be able to calculate the following areas more accurately: Epon area, tissue area, and tissue area occupied by perikarya. From these values, neuropil area was calculated by subtracting perikaryal and blood vessel lumen area from tissue area. The areal densities were obtained by calculating the ratio of the number of neuronal and astrocytic profiles per neuropil area. We consider this analysis to be semiquantitative, rather than quantitative, because we cannot ascertain the age-dependent and interexperimental variabilities in immunodetection. We attempted to minimize underestimations of labeling by sampling ultrathin tissue strictly from the tissue-Epon interface, where penetration of immunoreagents would be maximal. Interexperimental variabilities were min- imized by processing tissue of different ages in the same incubation buffer.

\section{Results}

\section{Specificity of the antiserum}

A rabbit polyclonal antiserum corresponding to a peptide of the C-terminal region of NMDA-R1 subunit (Moriyoshi et al., 1991) was developed. To ascertain the specificity of the antiserum employed, we conducted Western blot analysis of particulate fractions of COS-7 cells transfected with the whole open reading frame of NMDA-R 1 as well as particulate fractions of dissected brain regions. Whereas the cloned NMDA-R1 gene has a predicted molecular weight of $105 \mathrm{kDa}$, the expressed rat NMDAR1 migrates with an apparent $M_{r}$ of $\sim 110 \mathrm{kDa}$ (Fig. 1). Particulate fractions from dissected brain regions exhibit immunoreactive NMDA-R 1 proteins with mobilities similar to the expressed cDNA products (Fig. 2). The relative abundance of NMDA-R1 differs in brain regions, with NMDA-R1 immunoreactivity predominating in the caudate-putamen and hippocampal formation and with barely detectable levels in the cerebellum and brainstem (Fig. 2). Staining is completely eliminated in COS-7 cell particulate fractions (Fig. 1) and brain regions (data not shown) by preadsorption with excess peptide, thereby demonstrating the specificity of the antibodies.

\section{Global distribution of NMDA-RI immunoreactivity}

Immunocytochemistry reveals a heterogeneous distribution of NMDA-R1 immunoreactivity within rat brain (Fig. 3). The distribution closely parallels that for NMDA receptors as revealed by receptor autoradiography (Monagham and Cotman, 1985; Maragos et al., 1988; Sakurai et al., 1991). For example, in the cerebral cortex, the immunoreactivity is slightly higher anteriorly than caudally; in the hippocampal formation, the CA1 region and the dentate gyrus exhibit slightly more immunoreactivity than the $\mathrm{CA} 3$ region. These patterns resemble those shown by NMDA receptor autoradiography. Other regions exhibiting detectable levels of NMDA-R1 immunoreactivity include the olfactory bulb, accumbens nucleus and caudate-putamen nuclei, dorsal thalamus, substantia nigra, superior colliculus, deep cerebellar nuclei, pontine nuclei, and the cerebellar cortex. In contrast, immunoreactivity in the white matter, such as the corpus callosum, is not detectable. Labeling in all regions is abolished completely by preadsorption of the antiserum with the synthetic peptide used for immunization, thus indicating high specificity of the immunoreactivity.

\section{NMDA-R1 immunoreactivity in the visual cortex of adult brains (PND 30 and older)}

NMDA-R1 immunoreactivity is readily detectable in neuronal perikarya and dendrites by light microscopy (Fig. 4). The laminar distribution of immunoreactive perikarya parallels the laminar density of all perikarya as revealed by Nissl stains. Accordingly, lamina 1 exhibits the lowest density of immunoreactive perikarya (Fig. 4A), while lamina 5 exhibits immunoreactivity within large-diameter perikarya and their apical dendrites (Fig. $4 B$ ). Many of the immunoreactive perikarya in lamina $6 \mathrm{~B}$ are elongated horizontally (Fig. 4C). Nucleoplasms of the cell bodies are consistently devoid of labeling (Fig. $4 B$ ). Electron microscopy reveals that somatic labeling is associated with the endoplasmic reticulum and Golgi apparatus (not shown).

In addition to perikarya, immunoreactivity is prevalent throughout the intercellular neuropil as punctate processes that 


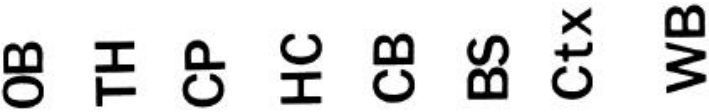

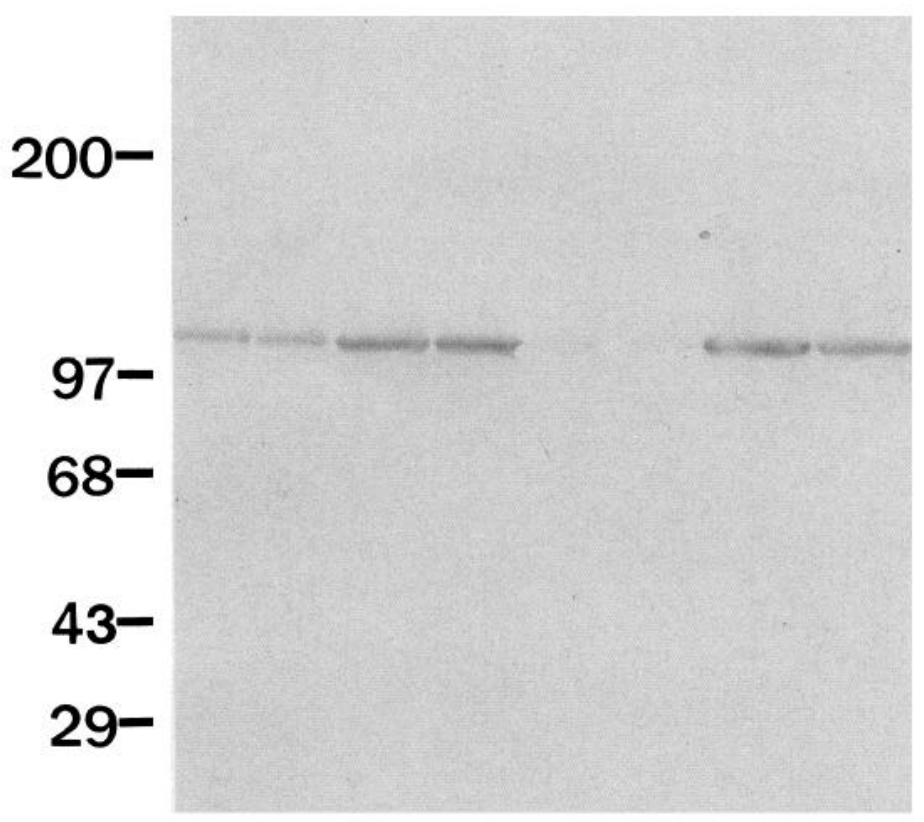

are just resolvable by Nomarski optics light microscopy $(\sim 0.2$ $\mu \mathrm{m}$ in diameter). Electron microscopy shows that punctate immunoreactivity reflects labeling in dendrites, axons, and astrocytes. Immunoreactivity is prevalent within dendrites, particularly over the postsynaptic densities within spines (Fig. 5). Semiquantitative analysis showed that of the 387 labeled profiles identified in lamina 1,27\% were dendritic, the majority of which showed peroxidase reaction products directly over postsynaptic densities. Unlabeled synapses, both of the symmetric and asymmetric types, exist in the immediate vicinity of labeled junctions. In addition, dendritic profiles lacking synapses within the plane of ultrathin section also are immunoreactive. In some cases, immunoreactivity continues beyond the postsynaptic density and is associated with the adjacent nonsynaptic portions of the plasma membrane as well as intracellularly (Fig. 5C). Within dendritic profiles exhibiting asymmetric junctions (Gray type 1), immunoreactivity rarely is restricted to nonsynaptic portions of the plasma membrane.

A substantial portion of the immunoreactive profiles are axonal. Specifically, at PND $30,16 \%$ of the immunoreactive profiles $(n=411)$ were identifiable as axonal, and in an older animal $49 \%$ of the profiles in the superficial laminae $(n=177)$ were identifiably axonal. The immunoperoxidase reaction product is usually over synaptic vesicles (Fig. $5 B$ ), although clusters of peroxidase reaction product can extend to nearby plasma membrane patches. Immunoreactive axon terminals form asymmetric synaptic junctions with spines and occasionally with dendritic shafts. In some cases, the immunoreactive axon terminals occur immediately adjacent to immunoreactive spines, although synaptic junctions between two such profiles are not always evident (Fig. 5B).

Laminar analysis indicates that the association of NMDA$\mathrm{R} 1$ immunoreactivity with synapses is more prevalent in lamina 1 ( $41 \%$ of all synapses; two labeled synapses $/ 100 \mu \mathrm{m}^{2}$ of neuropil area) than in laminae $4 / 5$ (11\% of all synapses; 0.5 labeled

\section{NMDA-R1}

Figure 2. The regional differences in immunoreactivity to the NMDA-R1 antibody as revealed by Western blot analysis. Membranes from various brain regions were subjected to SDS-PAGE, and then reacted with the NMDA-R1 antibody $(1: 1000)$. The NMDA-R 1immunoreactive band is in fractions of the caudate-putamen $(C P)$, hippocampal formation $(H C)$ and cerebral cortex $(C t x)$, the cerebellum $(C B)$, brainstem $(B S)$, olfactory bulb $(O B)$, thalamus $(T H)$, and whole brain $(W B)$. synapse $/ 100 \mu \mathrm{m}^{2}$ of neuropil area) or lamina $6 \mathrm{~B}(6 \%$ of all synapses; 0.1 labeled synapse $/ 100 \mu \mathrm{m}^{2}$ of neuropil area). The areal density of labeled profiles (dendritic + axonal + astrocytic + unidentifiable) also is greater in the superficial laminae (7.81/ $100 \mu \mathrm{m}^{2}$ in lamina 1) than in the deeper laminae $\left(2.25 / 100 \mu \mathrm{m}^{2}\right.$ in laminae $4 / 5,2.45 / 100 \mu \mathrm{m}^{2}$ in lamina 6B). In lamina 1, dendritic labeling is as prevalent as glial labeling ( $26 \%$ and $24 \%$, respectively; $n=356$ ). On the other hand, many more of the labeled profiles in the deeper laminae are glial rather than dendritic ( $57 \%$ and $27 \%$, respectively; $n=90$ ), identified by the tortuous plasma membrane that interleaves among axonal and dendritic profiles (Peters et al., 1991).

\section{NMDA-R1 immunoreactivity in the visual cortex of PND 2 and PND 4 brains}

Light microscopy demonstrates that the laminar distribution of NMDA-R1 immunoreactivity in the visual cortex of PND 2 and PND 4 tissue is markedly different from that seen in adulthood. Rather than the uniform, perikaryal labeling seen in adulthood, the youngest neonatal tissue exhibits staining in a few perikarya of laminae 5 and $6 \mathrm{~B}$ (Fig. $6 \mathrm{~B}$ ) and minimally in the cortical plate (the future laminae 2,3 , and 4 ). The immunoreactive neuronal perikarya in lamina 5 bear thick and thin immunoreactive processes (Fig. $6 D$ ) that emanate from cell bodies at various angles. Those in lamina $6 \mathrm{~B}$ are without immunoreactive processes (Fig. $6 E$ ). Some of the finer varicose processes in these laminae also are immunoreactive. Within the cortical plate, numerous punctate profiles are apparent, as are radially oriented bundles of processes (Fig. $6 \mathrm{C}$ ). Neuropil labeling is most intense in the future lamina 1 , commonly referred to as the marginal zone at this age (Kageyama and Robertson, 1993) (Fig. 6B,C).

Electron microscopy demonstrates that, within neuronal perikarya of PND 2 and 4 tissue, immunoreactivity is associated with organelles synthesizing plasma membrane proteins, that 
A

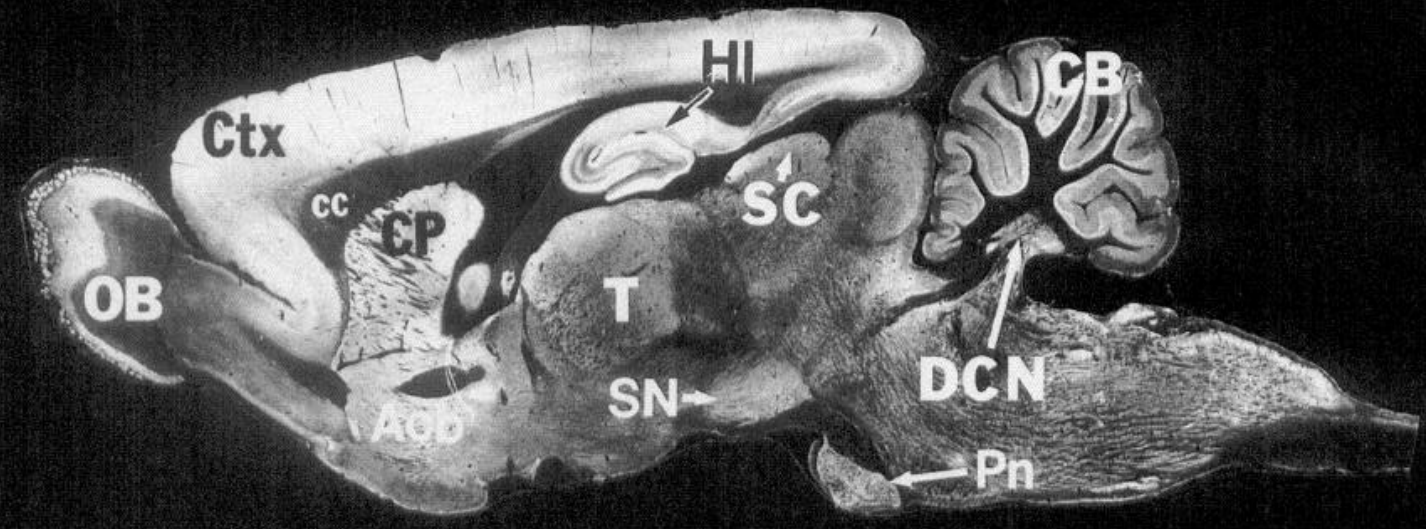

B

NMDA -R1 

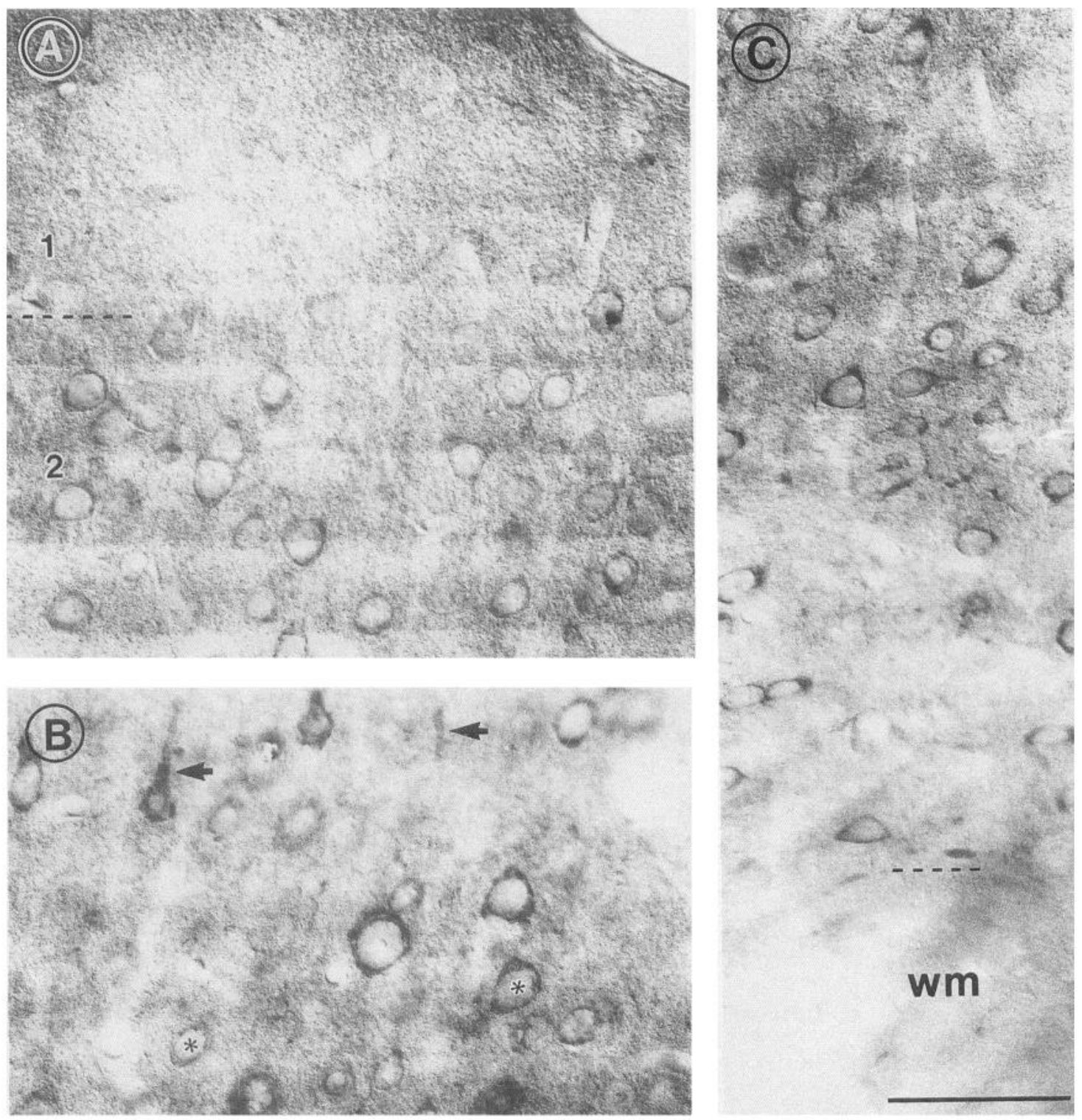

Figure 4. The light micrographs show NMDA-R1 immunoreactivity in the adult visual cortex. The panels show details of the supragranular laminae $(A)$, lamina $5(B)$, and laminae $6 \mathrm{~A}, 6 \mathrm{~B}$, and the white matter $(\mathrm{wm})(\mathrm{C})$, respectively. All laminae exhibit immunoreactive perikarya of varying diameters and shapes. The neuropil also exhibits numerous punctate immunolabeling. The nucleoplasm is consistently unlabeled (asterisks in $B$ ). Arrows in $B$ show labeling in the apical dendrites. Scale bar, $50 \mu \mathrm{m}$ (for all panels).

is, the rough endoplasmic reticulum and the Golgi apparatus (Fig. 7A). At the Golgi apparatus, immunoreactivity is along the Golgi saccule surfaces facing the cytoplasm. Besides these intracellular organelles, perikaryal immunoreactivity can be found at immature axosomatic synapses (Fig. $7 B$ ).

Electron microscopy reveals that the intense immunoreactivity in the marginal zone consists of dendritic and axonal labeling. Most frequently, immunoreactivity is associated with large surfaces of dendritic plasma membrane that are devoid of synaptic specializations or contacts with profiles identifiable as axon terminals (Fig. 8). Synapses, labeled or unlabeled, are scarce at this age $\left(0.37 / 100 \mu \mathrm{m}^{2}\right.$ of neuropil area at PND 2 and $0.86 / 100 \mu \mathrm{m}^{2}$ of neuropil area at PND 4 in the superficial layer) and only about $10 \%$ (5 of 45 ) of the identifiably dendritic synapses in the superficial laminae are immunoreactive. In cases where labeling is associated with postsynaptic membranes, the presynaptic terminals contain few irregularly shaped vesicles that are dispersed (Fig. 8). It is difficult to discern whether the immunoreactive

Figure 3. A, Immunocytochemistry reveals a heterogeneous distribution of NMDA-R1 immunoreactivity in the adult rat brain. The highest density of immunoreactivity occurs in the anterior cingulate cortex $(C t x)$, olfactory bulb $(O B)$, and the hippocampal formation $(H I)$. A slightly lower level of immunoreactivity occurs in the posterior cingulate cortex, the caudate-putamen nucleus $(C P)$, and the accumbens nucleus $(A c b)$. Moderate labeling is apparent in the thalamus $(T)$, substantia nigra $(S N)$, superior colliculus $(S C)$, Purkinje cell layer of the cerebellum $(C B)$, deep cerebellar nucleus $(D C N)$, and the pontine nucleus $(P n)$. Immunoreactivity is minimal in the corpus callosum $(c c)$ and the white matter region of the olfactory bulb. $B$, Preadsorption of the antibody with the antigen abolishes immunoreactivity throughout the brain. 

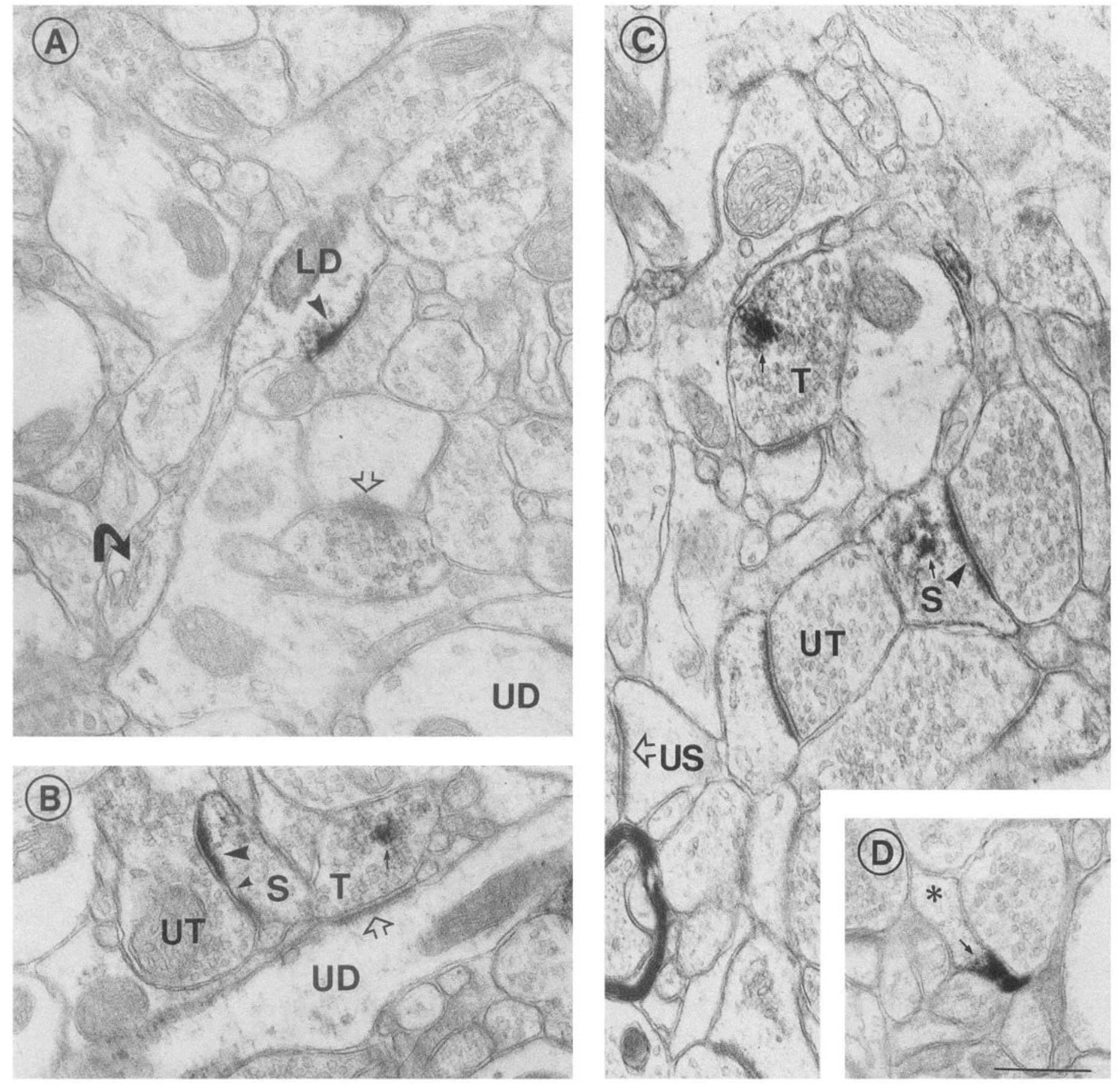

Figure 5. Electron micrographs showing NMDA-R1 immunoreactivity in the neuropil of the adult supragranular visual cortex. $A$, NMDA-R 1 immunoreactivity is highly localized to the postsynaptic density (arrowhead) of a dendrite $(L D)$. The spine apparatus (curved arrow) is unlabeled. Open arrow points to an unlabeled postsynaptic density. $B$, NMDA-R1 immunoreactivity sometimes occurs in pre- and postsynaptic profiles that are adjacent but without apparent synaptic junctions. $S$, labeled dendritic spine; large arrowhead, labeled postsynaptic density; small arrowhead, perforation of the density; small arrow in the adjacent terminal $(T)$, a discrete patch of labeling. $U D$, unlabeled dendrite; open arrow, unlabeled postsynaptic density. $C$, NMDA-R1 immunoreactivity in dendritic spines is not always localized exclusively over postsynaptic density. Arrowhead in the spine $(S)$ points to a labeled postsynaptic density. Small arrow in $S$, clump of cytoplasmic immunoreactivity. US, unlabeled spine; open arrow in $U S$, unlabeled postsynaptic density; $T$, labeled terminal (small arrow points to a clump of labeling); $U T$, unlabeled terminal. $D$, Glial labeling. Asterisk is placed in the cytoplasm of a distal astrocytic process. Scale bar, $450 \mathrm{~nm}$ (for all panels).

postsynaptic densities are thick or thin (belonging to type I or type II synapses) (Gray, 1959), due to coating of the organelle by immunoperoxidase reaction products. In contrast, none of the dendritic synapses in the lamina 5 or $6 \mathrm{~B}$ are immunoreactive.
Immunoreactive axons are not detectable at PND 2. At PND 4 , immunoreactive axons are more prevalent in lamina $5(0.12 /$ $100 \mu \mathrm{m}^{2}$ of neuropil area) than in the marginal zone $(0.02 / 100$ $\mu \mathrm{m}^{2}$ of neuropil area) and are not detectable in lamina 6B. Immunoreactive profiles are identifiable as axons by the pres- 

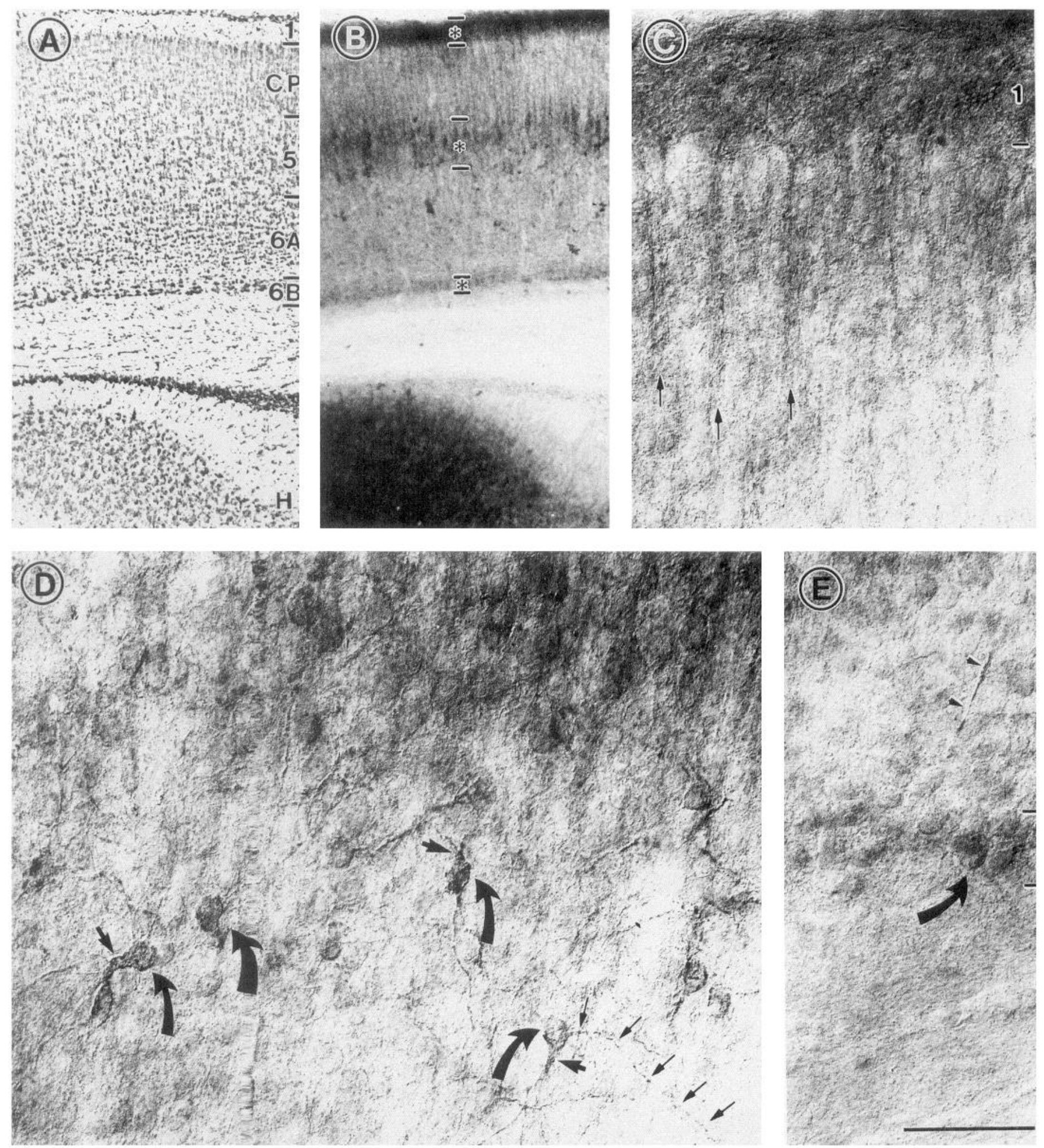

Figure 6. Light micrographs of PND 4 visual cortex exhibit a highly laminar distribution of NMDA-R1 immunoreactivity. $A$, Nissl stain reveals laminar boundaries, numbered to the right; $C P$, cortical plate; 1 , future lamina 1 (marginal zone); $H$, hippocampus. $B$, An adjacent section immunolabeled using the anti-NMDA-R 1 antibody reveals intensely labeled bands (asterisks) in laminae 1,5 , and $6 \mathrm{~B}$. $C$, The marginal zone (future lamina 1), at a higher magnification, exhibits dense labeling throughout the neuropil. Below the marginal zone, immunoreactivity within bundles of apical dendrites is evident (small arrows). D. The immunoreactive perikarya in lamina 5 are polymorphic (curved arrows). Proximal dendrites emerging from these perikarya also are immunoreactive (large straight arrows). Many of them are unusually thick (e.g., leftmost arrow). Immunoreactivity is also detectable in the finer, varicose processes that appear axonal (small straight arrows). E. Neurons lined along lamina 6B (demarcated by two lines) are immunoreactive (curved arrow). In addition, granular labeling is evident in the underlying white matter. A few processes in lamina 6A, above, also are immunoreactive (arrowheads). Scale bar: $400 \mu \mathrm{m}$ for $A$ and $B, 50 \mu \mathrm{m}$ for $C-E$. 

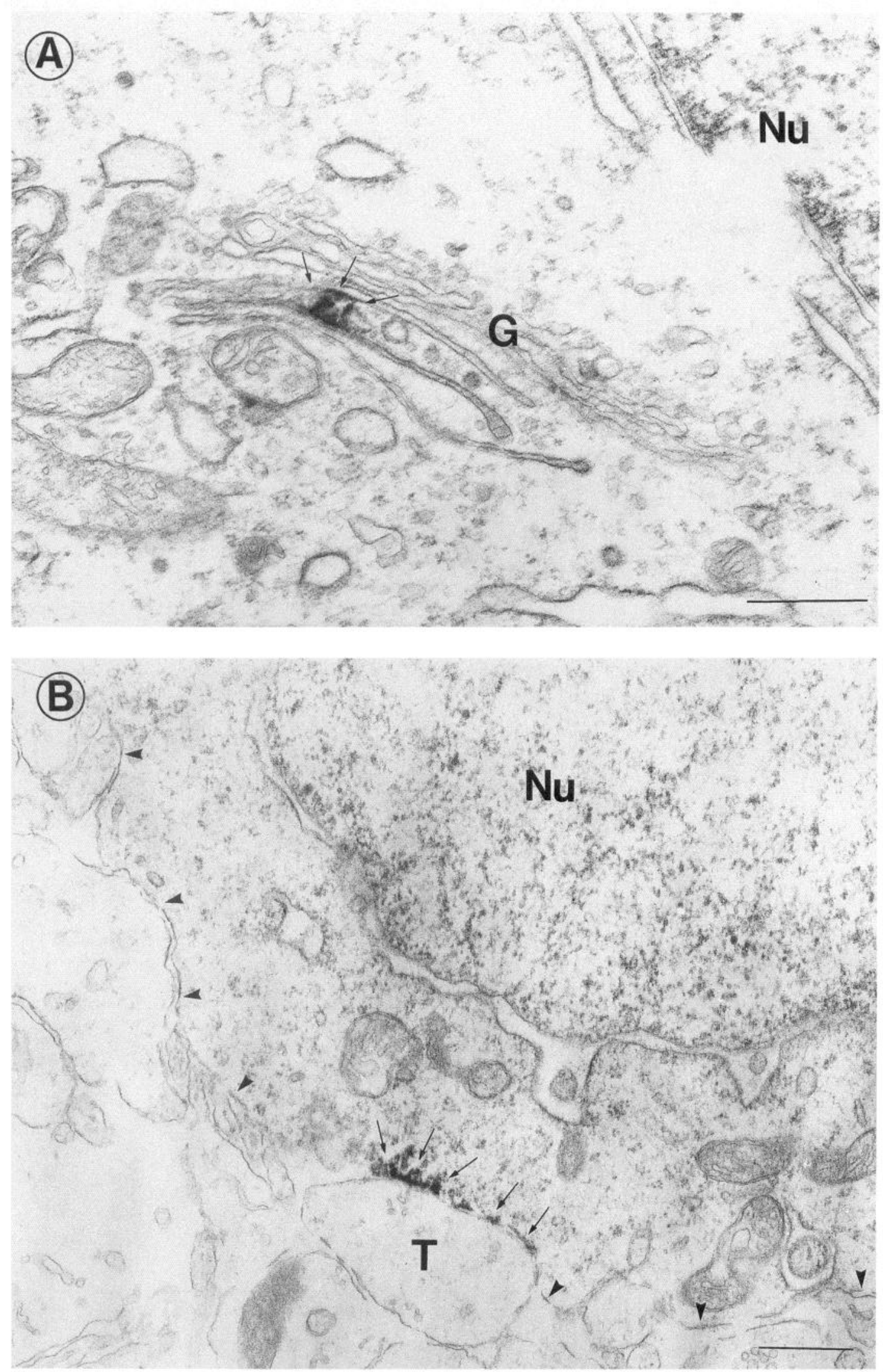

Figure 7. Electron micrographs taken from the supragranular laminae of PND 4 visual cortex show NMDA-R1 immunolabeling in neuronal perikarya. $A$, The Golgi apparatus $(G)$ in the neuronal cell body shows discrete labeling between the stacked saccules (arrows). $B$, Plasma membrane of a neuronal perikaryon exhibits highly localized immunolabeling over the postsynaptic specialization (arrows). Arrowheads, plasma membrane; $\mathrm{Nu}$, nucleoplasm; $T$, an immature terminal containing a few irregularly shaped vesicles. Scale bars, $450 \mathrm{~nm}$. 

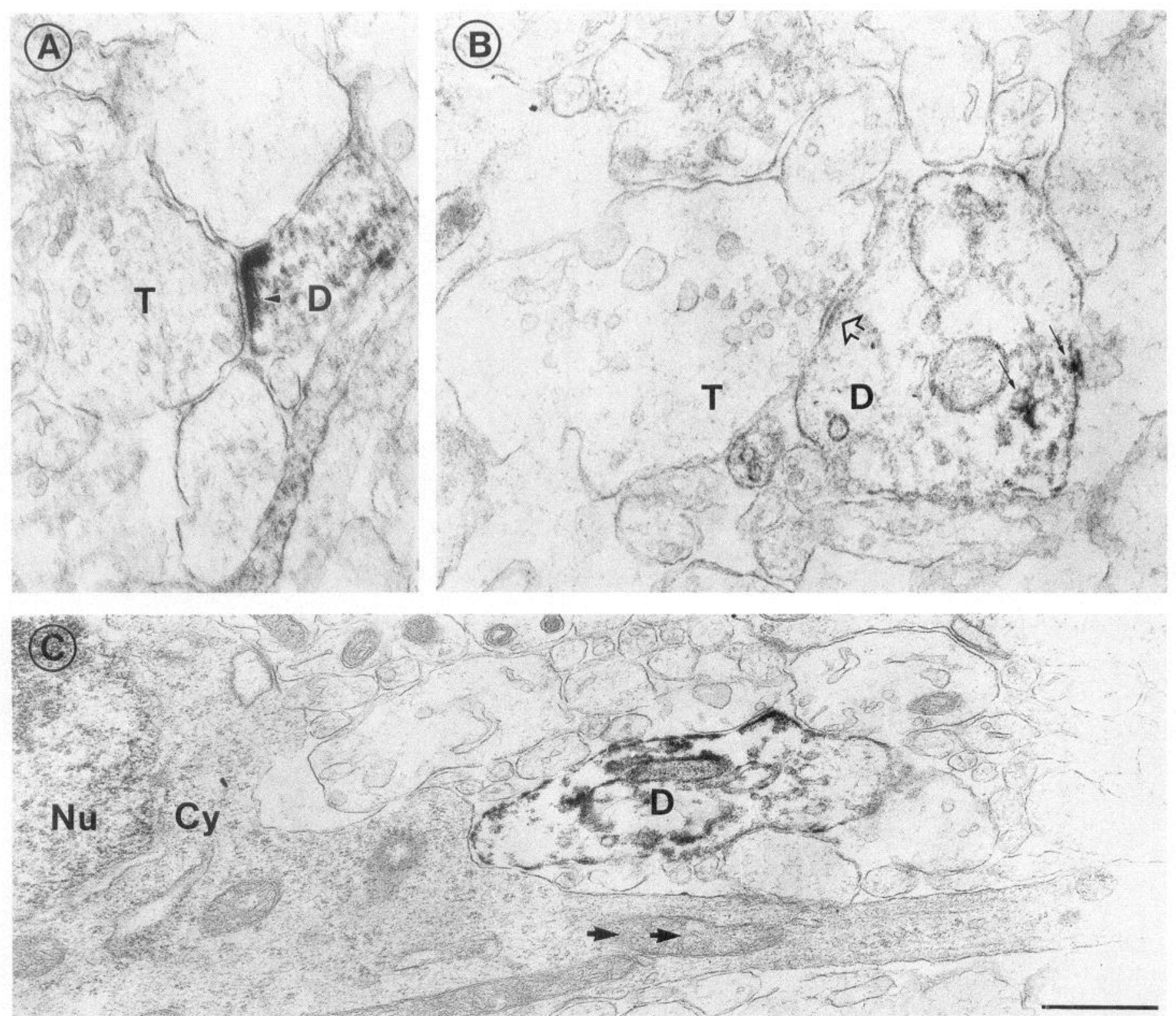

Figure 8. Electron micrographs taken from the supragranular laminae of PND 4 visual cortex show dendritic labeling that is both synaptic and nonsynaptic. $A$, Example of an intensely labeled postsynaptic density (arrowhead) within a dendrite $(D)$ containing a diffuse distribution of immunoreactivity. $T$, an unlabeled axonal terminal containing irregularly shaped vesicles. $B$, Example of a dendrite $(D)$ showing diffuse labeling in the cytoplasm and along the plasma membrane (small arrows) but not at the synaptic junction (open arrow). $C$, Example of an immunoreactive dendrite $(D)$ lacking apparent synaptic associations. Immunoreactivity occurs along the plasma membrane and intracellularly. $N u$ and $C y$, nucleoplasm and cytoplasm of a glial process contacting dendrite $D$. The $t w o$ arrows point to an elongated process emanating from the glial perikaryon. Scale bar, $450 \mathrm{~nm}$ (for all panels).

ence of numerous vesicles in the cytoplasm (Fig. 9). Most of the immunoreactive axons lack identifiable synaptic junctions, however (five of six, observed in lamina 5) (Fig. 9B).

In contrast to adult tissue, PND 2 and PND 4 tissues lack immunolabeled profiles identifiable as glial in any of the laminae.

\section{NMDA-R1 immunoreactivity in PND 6-10 visual cortices}

Toward the end of the first postnatal week, a distinct band of immunoreactivity emerges in lamina 4 (Fig. 10B). The band consists of immunoreactive perikarya resembling those occurring in lamina 5 of PND 4 visual cortices. Immunoreactivity persists in lamina 5 but is more diffuse than in lamina 4 . Ex- amination of lamina 5 at a higher magnification (Fig. 10C) reveals that immunoreactivity consists of labeling in perikarya and fine varicose processes, as seen at PND 2 and 4 . In contrast to the dendritic processes seen emanating from labeled perikarya at PND 4, processes emerging from lamina 5 perikarya at PND 6-7 are thinner and studded with punctate labeling.

The laminar distribution of immunoreactivity at PND 9 is similar to that seen at PND 6 and 7 (Fig. 11A). Closer inspection, however, reveals the presence of immunoreactive perikarya and fine varicose processes in the supragranular laminae, 2 and 3 (arrows in Fig. 11D). These appear similar to those seen in laminae 4 and 5 at PND 6-7. Labeling of perikarya and processes in laminae 4 and 5 persists (Fig. $11 C$ ). Immunoreactive 

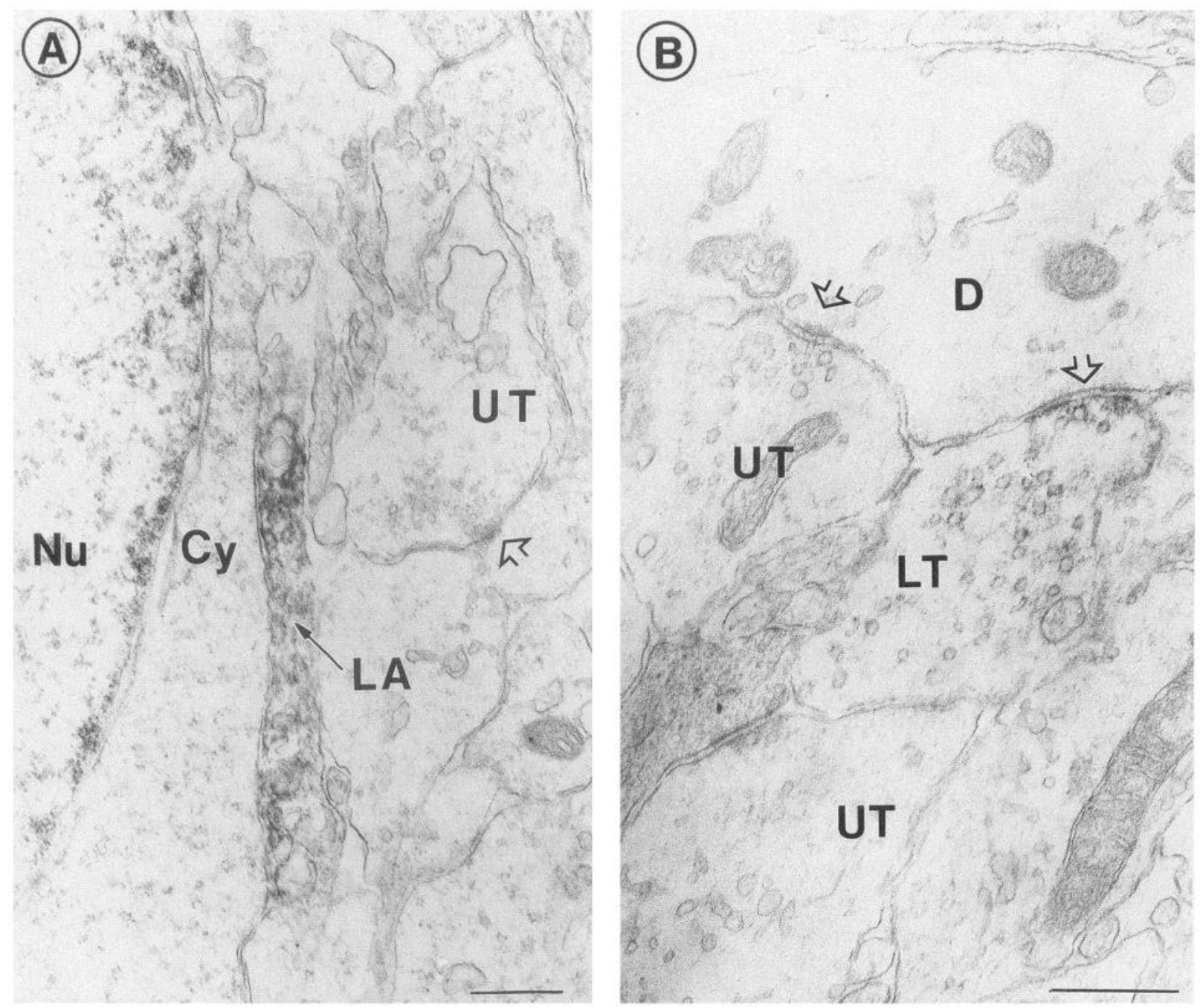

Figure 9. Electron micrographs taken from the supragranular laminae of PND 4 visual cortex show that axons also are immunoreactive. $A$, An axon $(L A)$ coursing next to a neuronal perikaryon is immunoreactive. Although the axon contains numerous vesicles, synaptic junctions with adjacent profiles are not evident. $N u$ and $C y$, nucleoplasm and cytoplasm of the cell body. $B$, An axon terminal exhibits weak immunoreactivity for NMDA-R1 $(L T)$. LT is synaptically associated with an unlabeled dendrite $(D)$. UT, unlabeled terminal forming a synaptic junction with an unlabeled dendrite; open arrow, unlabeled postsynaptic density. Scale bar, $450 \mathrm{~nm}$ (for all panels).

processes in lamina 1 are more dispersed, allowing for the visualization of individual processes (Fig. $11 B$ ).

Electron microscopic examination of lamina 1 indicates that the areal density of synapses (labeled and unlabeled) has more than doubled from PND $4\left(2.46 / 100 \mu \mathrm{m}^{2}\right.$ of neuropil area at PND 7; $0.86 / 100 \mu \mathrm{m}^{2}$ of neuropil area at PND 4). The proportion of labeled synapses, however, remains constant at $10 \%$ (19 of 190 synapses encountered in lamina 1 of PND 7 and 9 tissue). The areal density of synapses is lower in the middle layer $\left(1.3 / 100 \mu \mathrm{m}^{2}\right.$ of neuropil area at PND 7) than in lamina 1 . The proportion of labeled synapses, however, is similar to that seen in lamina 1 ( $12 \%$ of 81 synapses). In contrast, lamina $6 \mathrm{~B}$ exhibits very few synapses $\left(0.19 / 100 \mu \mathrm{m}^{2}\right.$ of neuropil area at PND 7) and most of these are not detectably immunoreactive.

\section{NMDA-R1 immunoreactivity in PND 14 and PND 18 visual cortices}

PND 14 and PND 18 tissue continues to exhibit two laminar bands of immunoreactivity, positioned in laminae 1 and 5 .
Unlike the younger tissue, PND 18 visual cortex shows an even distribution of perikaryal labeling across laminae 2-6. The morphology of labeled perikarya resembles that seen in adulthood in that perikarya exhibit clearly unlabeled nucleoplasm and bear dendrites that are positioned basally and apically (Fig. 12C,D). However, unlike adult tissue, the intensity of perikaryal labeling is heterogeneous, with most perikarya exhibiting very light staining. Immunoreactivity is also evident in numerous fine, varicose processes (Fig. 12C-E).

Electron microscopic examination of lamina 1 reveals that the immunoreactive processes consist of axons and dendrites. These are considerably more numerous than in younger stages (3.53 labeled profiles/100 $\mu \mathrm{m}^{2}$ of neuropil area at PND 14;8.1/ $100 \mu \mathrm{m}^{2}$ of neuropil area at PND 18). Unlike the pattern seen at earlier stages, labeling within dendrites is more discretely localized to spine heads (Fig. 13A,B). Correspondingly, labeling along the plasma membrane of large-caliber dendrites is less than in younger tissue. The areal density of synapses in lamina 1 has increased more than 30 -fold from PND $2\left(3.53 / 100 \mu \mathrm{m}^{2}\right.$ of neuropil area at PND $14 ; 9.39 / 100 \mu \mathrm{m}^{2}$ of neuropil area at 

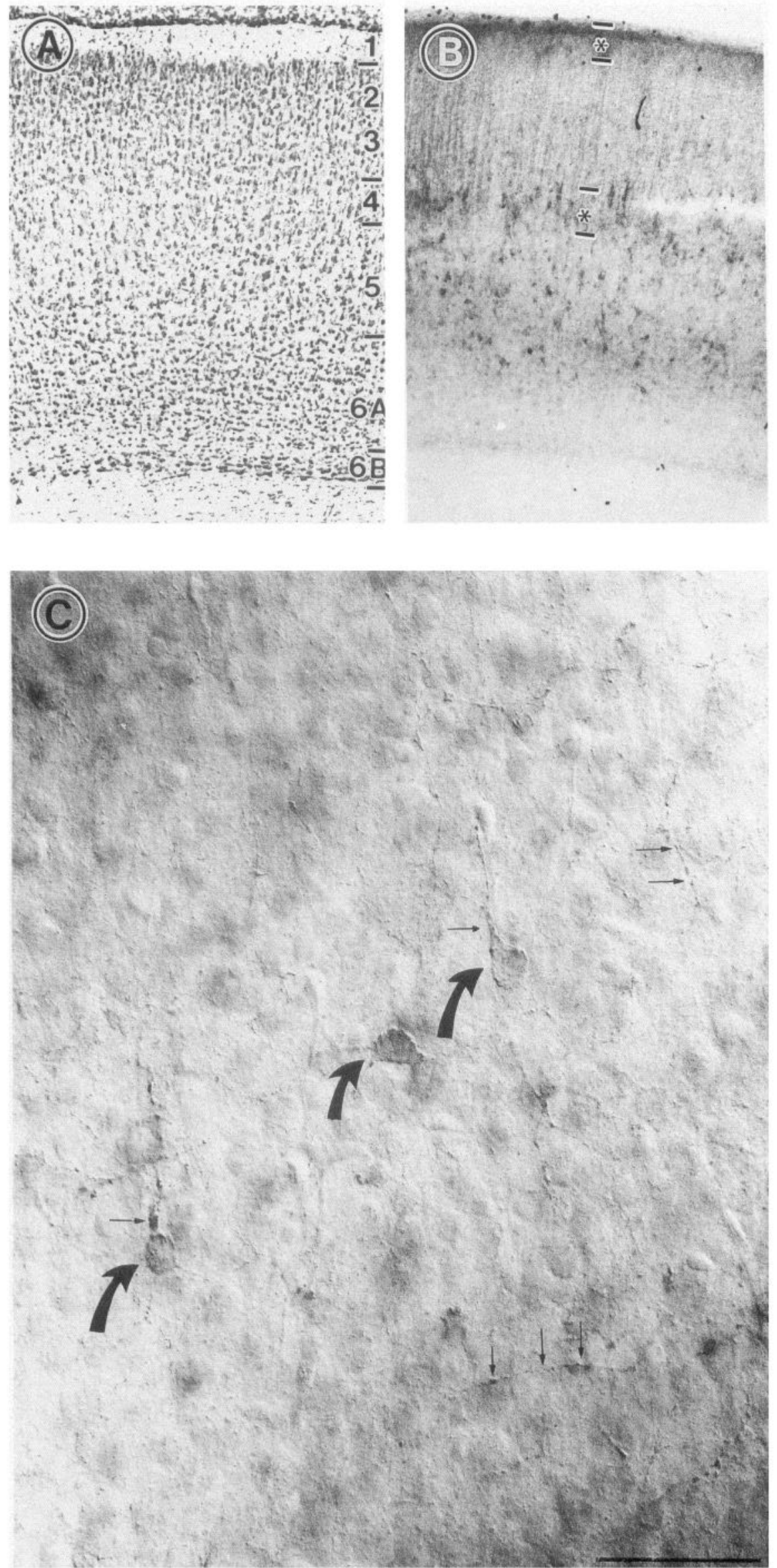

Figure 10. NMDA-R1 immunoreactivity in PND 6 visual cortex. $A$, Nissl stain reveals the laminar boundaries (indicated on the right side). $B$, NMDAR1 immunoreactivity is laminarly distributed. Lamina 1 (upper asterisk) exhibits dense neuropilar immunoreactivity, as seen at PND 4. A new band, corresponding in position to lamina 4 , has appeared (lower asterisk). Intensely immunoreactive perikarya are scattered below, in lamina 5 . The white matter (below 6B) is the least immunoreactive. $C$, Perikarya in lamina 5 , shown at a higher magnification. Immunoreactivity rims perikarya (curved arrows) and the processes emerging from them (small arrows). The emerging processes are thinner than seen at PND 4. Fine varicose processes in the region also are immunoreactive (small, paired, and triplet arrows). Scale bar: $400 \mu \mathrm{m}$ for $A$ and $B, 50 \mu \mathrm{m}$ for $C$. 

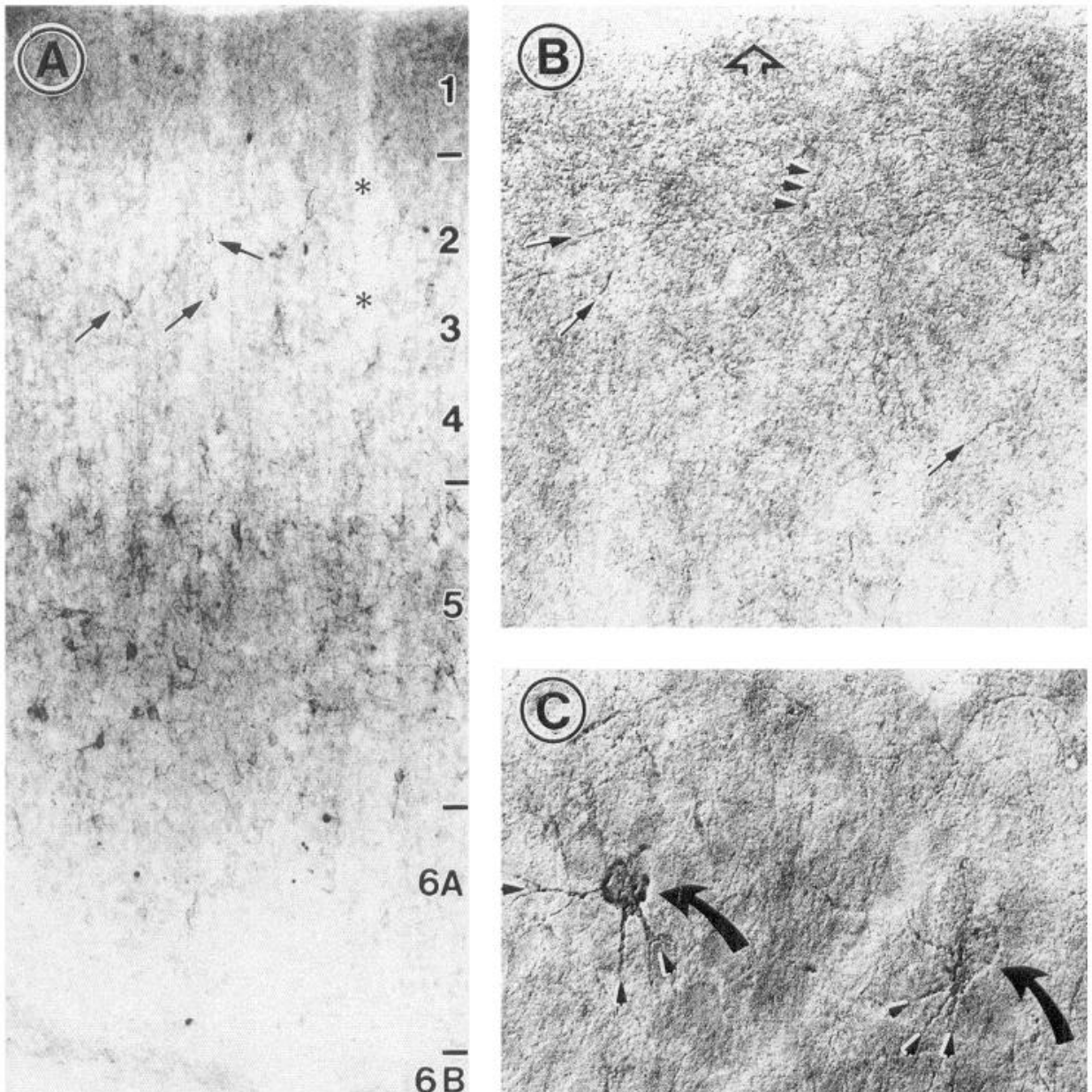

Figure 11. NMDA-R1 immunoreactivity in PND 9 visual cortex. $A$, Numbers to the right indicate the cortical laminae. Laminae 1 and 5 show high levels of neuropil labeling. Immunoreactive perikarya also are numerous in lamina 5. A few neurons in laminae $2 / 3$ also are immunoreactive (arrows). Fine, vertically oriented processes in lamina 4 may be apical dendrites. Asterisks denote blood vessel lumens. $B$, Lamina 1 , shown at a higher magnification, exhibits a fine mesh of processes. Solid arrows point to some of the individual processes. The triple arrowheads point to punctate labeling. The open arrow points to pial surface. $C$, Lamina 5 , at a higher magnification, exhibits immunoreactivity within perikarya (curved arrows) and dendritic processes (arrowheads) of multipolar neurons. $D$, Immunoreactive neuronal perikarya in laminae $2 / 3$ are surrounded by punctate immunolabeling (curved arrows). Immunoreactivity is also detectable in long, fine, varicose processes that appear axonal (small arrows). Scale bar: $400 \mu \mathrm{m}$ for $A, 50 \mu \mathrm{m}$ for $B-D$.

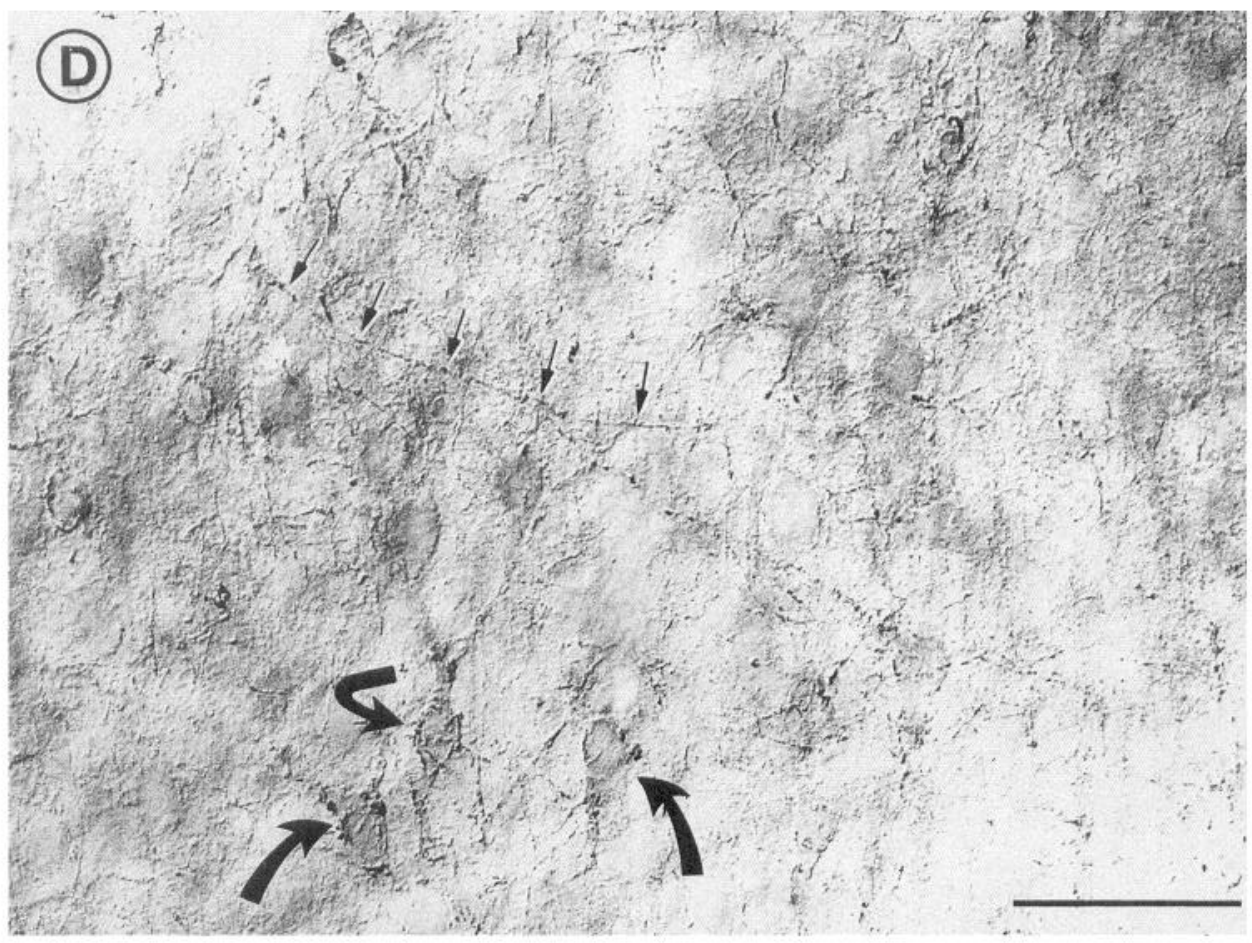


PND 18), yet the proportion of labeled synapses remains at about $10 \%$ (40 of 386).

Labeled axons in lamina 1 appear considerably more mature than those in PND 2 and PND 4 tissue (Fig. 13D,E). The vesicles are more numerous, clustered, and uniform in size. Not all of the immunoreactive axons exhibit synaptic junctions within the planes of ultrathin sections. However, where apparent, they form asymmetric junctions with dendrites. As noted in adult tissue, the most immunoreactive portion of the axonal process is usually away from the presynaptic membrane.

The areal density of labeled profiles in lamina $6 \mathrm{~B}$ is less than in the middle and superficial laminae $\left(2.71 / 100 \mu \mathrm{m}^{2}\right.$ of neuropil area at PND 14;2.3/100 $\mu \mathrm{m}^{2}$ of neuropil area at PND 18). As observed in the superficial laminae, labeling occurs within axonal processes and over postsynaptic densities in spines (Fig. $14 A$ ). Unlike the superficial laminae, however, many of the large-caliber dendrites still exhibit immunoreactivity along nonsynaptic portions of the plasma membrane (Fig. 14B).

At this stage, immunoreactivity along the plasma membrane of astrocytic processes is easily identifiable (Fig. 14C). Although few in number $(0.7 \%$ of 426 labeled profiles identified in PND 14 visual cortex; $8 \%$ of 321 labeled profiles in PND 18 visual cortex), these labeled astrocytes are distributed across the various laminae examined.

\section{Discussion}

Our results indicate that NMDA-R 1 immunoreactivity in the adult rat visual cortex occurs in dendrites, axons, and distal portions of astrocytes. Laminar analysis by electron microscopy indicates that NMDA-R1 immunoreactivity in the superficial laminae occurs most frequently at dendritic spines and axon terminals. By comparison, NMDA-R 1 immunoreactivity in the deeper laminae is sparser and more frequently occurring within astrocytes than in dendrites. During postnatal development, NMDA-R1 immunoreactivity is first found as large patches on nonsynaptic plasma membrane of perikarya and proximal dendrites. Over a 2 week period, the large nonsynaptic patches transform into smaller patches that are discretely localized to the postsynaptic density in spines. NMDA-R1 immunoreactivity is detectable first in dendrites (PND 2), followed by axons (PND 4), and finally in astrocytes (PND 14). In the discussion below, we consider the (1) specificity of the antiserum for recognizing NMDA-R 1 subunits; (2) relevance of the localization of NMDA-R 1 immunoreactivity in postsynaptic densities of spines, terminals, and astrocytes; and (3) significance of the developmental changes in the subcellular and laminar distribution of NMDA-R1 immunoreactivity.

\section{Specificity of the antiserum}

Our antibody was raised against a C-terminal peptide of the cloned NMDA-R1 subunit (Moriyoshi et al., 1991). Six additional isoforms of the NMDA-R 1 subunit exist through alternative splicing (Sugihara et al., 1992). All seven isoforms of the NMDA-R1 subunit have an identical C-terminus sequence. Thus, the antibody employed in this study recognizes all known NMDA-R1 subunits. Through PCR and cross-hybridization techniques (Nakanishi et al., 1992), four additional NMDA receptor subunits designated NMDA-R2A through NMDA-R2D have been identified. Individual NMDA-R2 subunits evoke no appreciable electrophysiologic response after agonist application, in contrast to NMDA-R 1 subunits. However, coexpression of NMDA-R2 subunits with NMDA-R1 subunits markedly potentiates the response to glutamate (Kutsuwada et al., 1992; Meguro et al., 1992; Monyer et al., 1992). Thus, NMDA-R1 serves as functional homo-oligomeric structure as well as a fundamental subunit of the heteromeric NMDA receptor complex with different NMDA-R2 subunits. Therefore, the antibody employed in this study recognizes all known potential homo-oligomeric NMDA-R 1 receptors and functional heteromeric NMDA receptor complexes.

The anatomical distribution of NMDA-R1 immunoreactivity closely parallels the distribution of NMDA-sensitive glutamate binding sites as revealed by receptor autoradiography. Receptor autoradiography shows that high densities of NMDA-sensitive glutamatergic receptors occur in the hippocampal formation, the olfactory bulb, the cerebral cortex, and caudate-putamen; intermediate densities in the cerebellar cortex and thalamus; and low levels in the brainstem (Monaghan and Cotman, 1985; Maragos et al., 1988; Sakurai et al., 1991). The immunocytochemical results are in accord with the receptor autoradiography results in that the immunoreactivity is decidedly less in the cerebellar cortex than in the olfactory bulb or neocortex. The immunocytochemical results match receptor autoradiography results even in details pertaining to individual anatomical regions. For instance, NMDA-R1 immunoreactivity in the cerebral cortex is higher anteriorly than caudally; within the hippocampal formation, the CA1 region and dentate gyrus exhibit higher densities than the $\mathrm{CA} 3$ region; and the lateral dorsal and the medial dorsal nuclei of thalamus exhibit higher NMDA-R1 staining than ventrally. These patterns parallel the distribution of NMDA binding sites (Monaghan and Cotman, 1985; Maragos et al., 1988; Sakurai et al., 1991). Together, the results indicate that the anti-NMDA-R1 antiserum used in this study recognizes the NMDA-RI subunit of the NMDA receptor with high specificity.

\footnotetext{
Figure 12. Light micrographs showing NMDA-R1 immunoreactivity in PND 18 visual cortex. $A$, Nissl-stained sections reveal the laminar boundaries as indicated to the right. $B$, Laminae 1 and 5 exhibit higher levels of immunoreactivity (asterisks). Arrows point to blood vessel lumens. $C$, At a higher magnification, laminae 1 and 2 exhibit neuropilar labeling. Perikarya labeling (curved arrow) resembles the adult pattern: an even distribution throughout perikaryal cytoplasm but no labeling in the nucleoplasm. A few varicose processes also are labeled (small arrows). $D$, Lamina 5, at a higher magnification, shows heterogeneous (light and dark) labeling in perikarya (curved arrows) as well as fine, long processes that are immunoreactive (small arrows). $E$, In lamina $6 \mathrm{~B}$, intensely stained perikarya are aligned in a single file (curved arrows). Radially oriented labeled processes (small arrows) are apparent in lamina 6A. Scale bar: $400 \mu \mathrm{m}$ for $A$ and $B, 50 \mu \mathrm{m}$ for $C-E$.

Figure 13. Electron micrographs showing NMDA-R1 immunoreactivity in the supragranular laminae of PND 18 visual cortex. $A$, A dendritic spine exhibits discrete labeling over the postsynaptic density (arrowhead) that is postsynaptic to an unlabeled terminal containing numerous vesicles $(T) . B$, Not all terminals presynaptic to an immunoreactive dendritic spine (arrowhead) appear mature. The terminal $(T)$ that is presynaptic to the labeled spine in this example contains fewer vesicles. $C$, Immunoreactivity occurs along and away from the plasma membrane of a dendrite $(L D)$ and an axon terminal $(T)$ that is presynaptic to an unlabeled dendrite $(U D)$. $D$, A cluster of vesicles within an axon $(L A)$ is intensely immunoreactive. Immunoreactivity is also associated with the plasma membrane. LA abuts an unlabeled axon $(U A)$. $E$, Within a favorable plane of section, a synaptic junction between a labeled axon terminal $(L T)$ and an unlabeled dendrite $(D)$ is evident. The open arrow points to the unlabeled postsynaptic density. Scale bar, $450 \mathrm{~nm}$ (for all panels).
} 
(A) (A) 1 $+2$ whos 3 whent $6+56+x=$ 4 watext

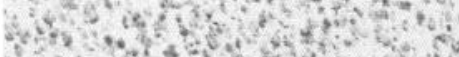

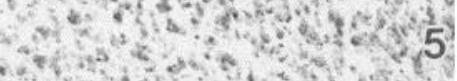

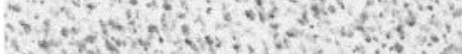

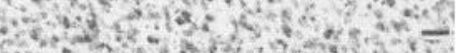

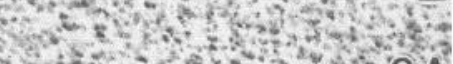
2. w $x$.

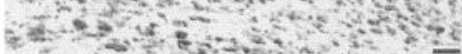
$\because \ldots-6 \bar{B}$

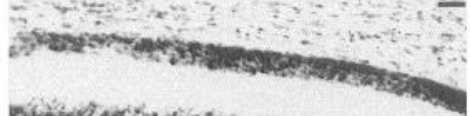

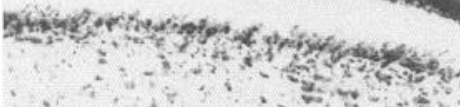

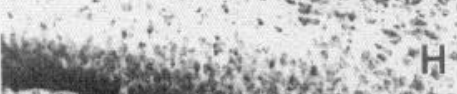
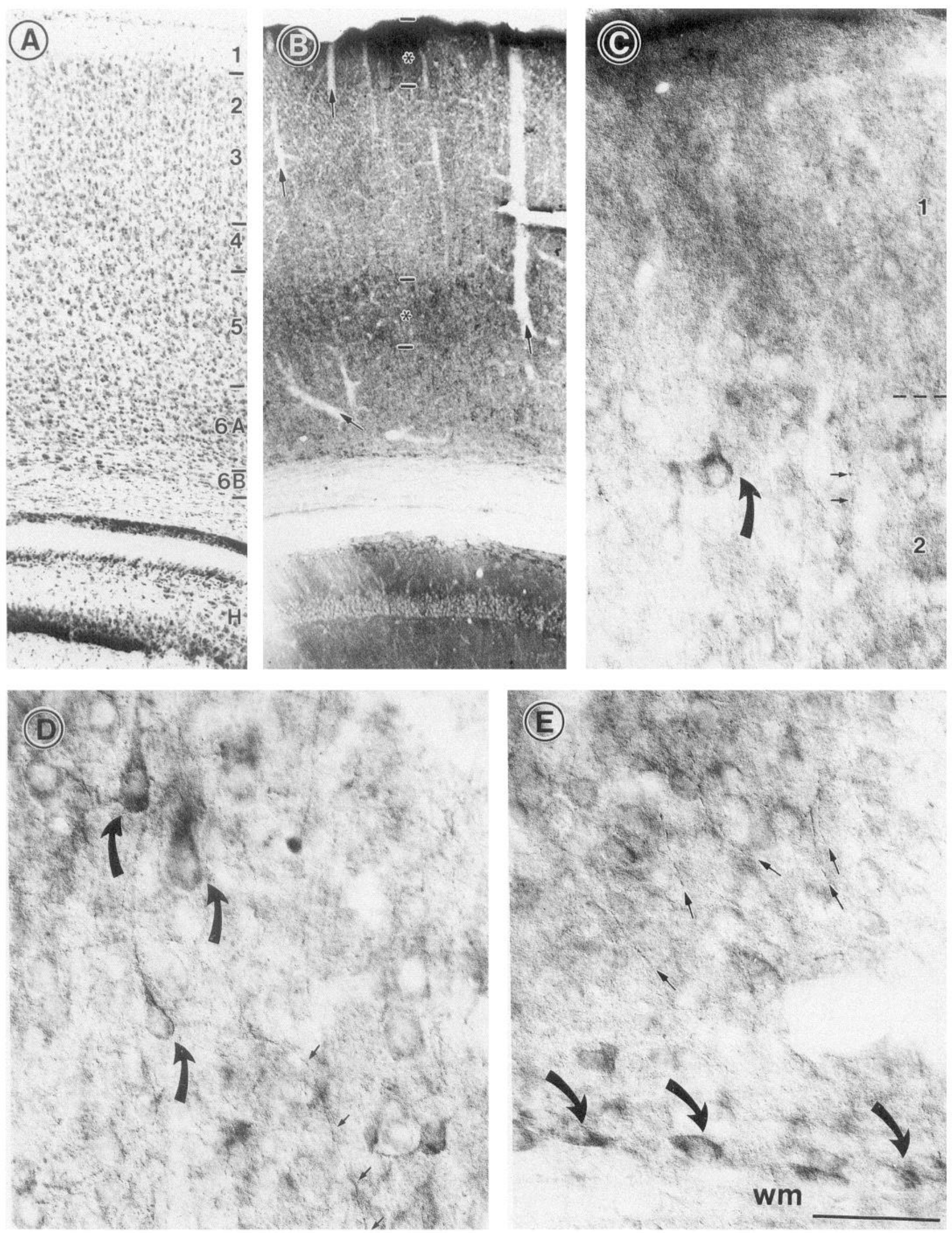

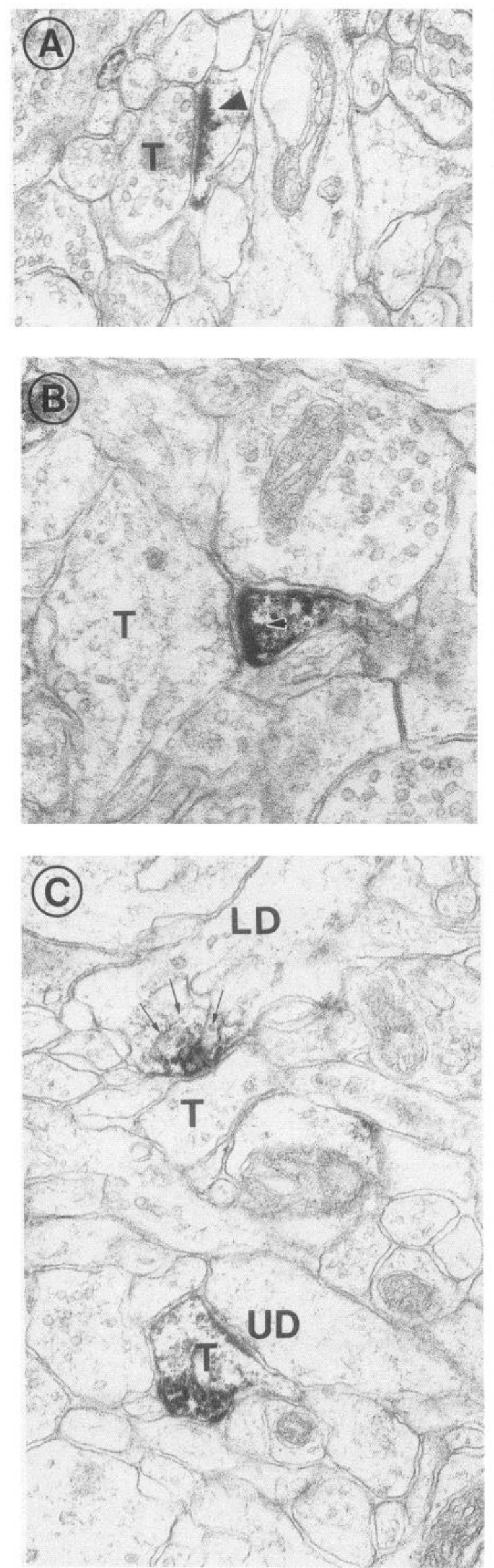
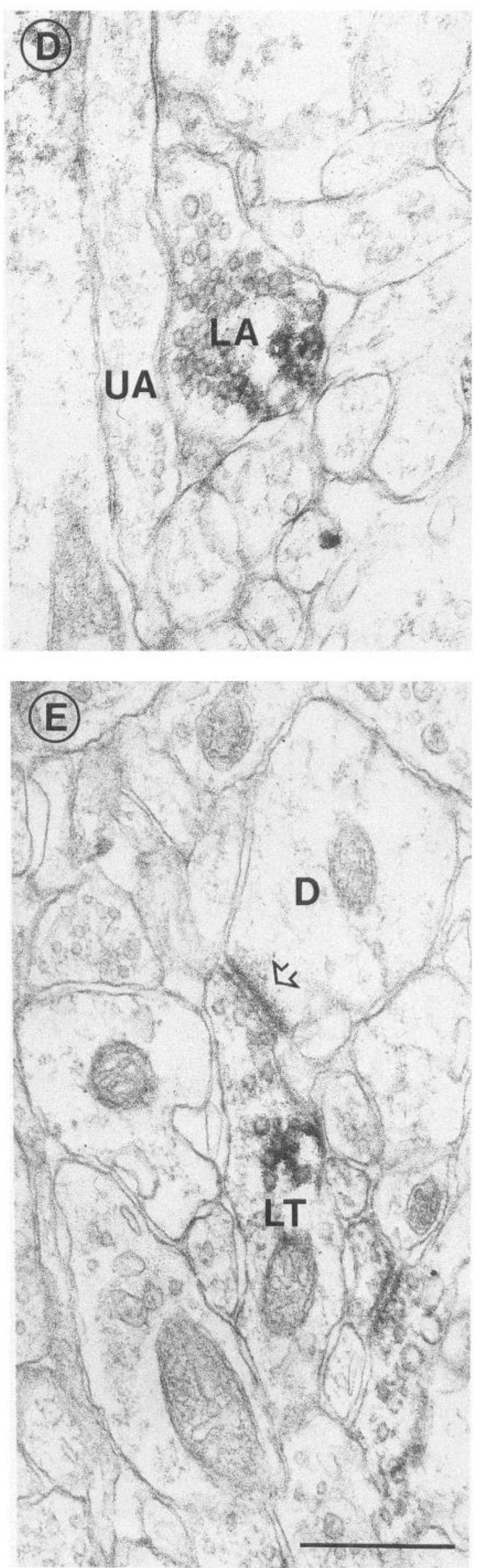

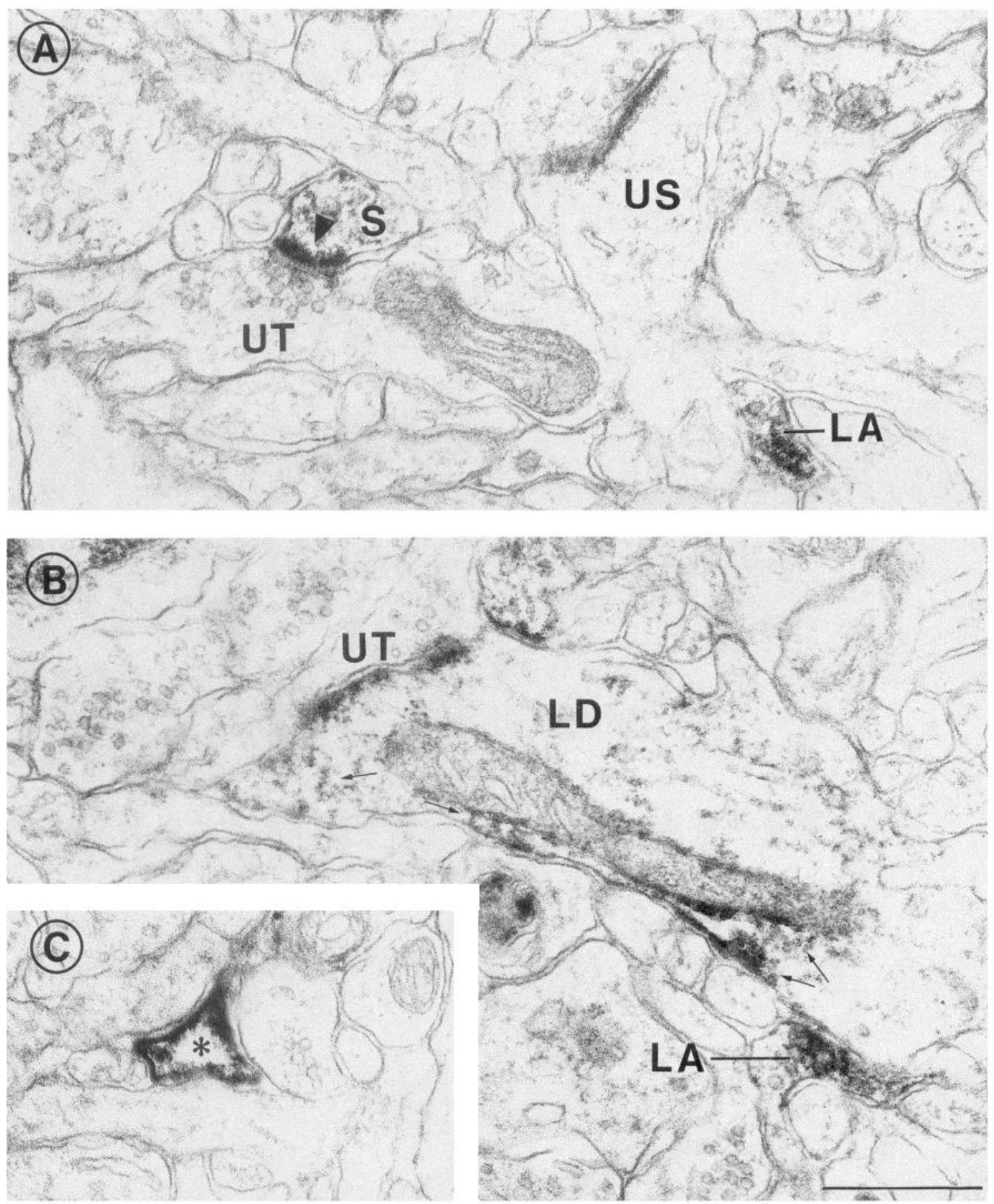

Figure 14. Electron micrographs showing NMDA-R1 immunoreactivity in the infragranular laminae of PND 18 visual cortex. A, A labeled spine $(S)$ exhibits discrete immunoreactivity over the postsynaptic density (arrowhead) that is associated with an unlabeled axon terminal (UT). An unlabeled spine is shown for comparison (US). A labeled axon also courses in the vicinity of the labeled spine $(L A)$. $B$, Not all dendrites at PND 18 show discrete immunoreactivity over the postsynaptic density. The labeling in this dendrite $(L D)$ is associated with the postsynaptic density but is also dispersed in the cytoplasm, nonsynaptic portions of the plasma membrane, and along mitochondria (arrows). The labeled plasma membrane is adjacent to a labeled axon $(L A)$. C, An astrocytic process exhibits immunoreactivity (asterisk). Its identification as an astrocyte is based on its small, irregular contour that abuts terminals (Peters et al., 1991). Scale bar, $450 \mathrm{~nm}$ (for all panels).

\section{Usefulness and limitations of the semiquantitative analysis}

For analyzing ontogenic changes in the laminar and subcellular distribution of immunoreactivity, we formed rough estimates of the areal density of immunoreactive and nonimmunoreactive profiles. The approach could not be considered quantitative, due mainly to the difficulty in controlling for interexperiment, interanimal, and interage variabilities in the efficiency of immunodetection. Nevertheless, we felt that our best attempts at estimating the relative areal densities would be useful for detecting age-dependent trends.

We sought to minimize variabilities in immunodetection by sampling portions of the ultrathin sections that were nearest to the surface of vibratome sections, since these portions have been 
shown by light microscopy to be maximally stained (Sternberger, 1986; C. Aoki, C. Venkatesan, C.-G. Go, J. A. Mong, and T. M. Dawson, unpublished observations). We also processed tissues from different ages within onc incubation chamber in order to minimize interexperimental variabilities. However, the ahsence of labeling cannot be interpreted simply as absence of the molecule, since immunodetection may be hampered by several factors, including the following: (1) loss of antigenicity due to tissue fixation, (2) stearic hindrance of the antigenic site due to the NMDA-R 1 subunit's interaction with other cytoplasmic molecules, (3) post-translational modification of the antigenic site that renders it no longer immunoreactive, and (4) failure of the immunoreagents to reach the antigenic site embedded in tissue.

\section{Dendritic spines of the adult visual cortex exhibit intense NMDA-Rl immunoreactivity}

In the superficial laminae of the adult visual cortex, postsynaptic densities of spines exhibit intense NMDA-R 1 immunoreactivity. One of the earliest electron microscopic studies suggested that excitatory synapses in the cerebral cortex form on spines (Gray, 1959). More recent immunoelectron microscopic results support this conclusion, since L-glutamate-immunoreactive axon terminals in the cerebral cortex (Aoki and Kabak, 1992) and elsewhere (Somogyi et al., 1986; Morrison et al., 1989) form asymmetric synaptic junctions that are predominantly on spines. Thus, the localization of NMDA-R 1 subunits directly over postsynaptic densities of spines is as expected and serves to confirm further that the antiserum recognizes glutamatergic receptors.

Within spines exhibiting NMDA-R 1 immunoreactivity, the immunoperoxidase reaction product is not always localized exclusively over postsynaptic densities. Immunoreactivity along nonsynaptic regions of the plasma membrane may result from lateral diffusion of the peroxidase reaction product. Alternatively, immunoreactivity that occurs detached from the postsynaptic density and intracellularly may reflect a pool of receptors that has undergone endocytosis or a newly synthesized pool that has yet to be inserted at the synaptic junction.

\section{NMDA-RI immunoreactivity at distal portions of astrocytes}

NMDA sensitivity is observed electrophysiologically in neonatal cortices throughout the laminae. However, visually evoked NMDA currents decrease in the granular and infragranular laminae with maturation (Fox et al., 1989). Our results agree with these findings, since we observed the majority of immunoreactive profiles in the deeper laminae to be dendritic up to PND 18 but become predominantly glial by PND 30 . Presumably, activation of astrocytic NMDA-R 1 subunits does not elicit biophysical responses that are easily detected electrophysiologically (but see Kirchhoff et al., 1993; Müller et al., 1993), and when they do the slower response time may prohibit assessment of the temporal correlation with visual stimulation. Activation of glial NMDA receptors has, indeed, been shown to trigger slow chemical and metabolic changes, such as astrocyte proliferation (Uchihori and Puro, 1993) and increased production of glial fibrillary acidic protein (Herrera and Cuello, 1992).

\section{Axons exhibit NMDA-RI immunoreactivity}

Most electrophysiological studies suggest that functional NMDA receptors reside postsynaptically (reviewed by Ascher and Nowak, 1987; MacDermott and Dale, 1987). However, neurochemical studies indicate the possibility that NMDA receptors also operate presynaptically as autoreceptors or heteroreceptors. Presynaptic autoreceptors are thought to regulate the release of L-glutamate (Martin et al., 1991; Bustos et al., 1992), and NMDA heteroreceptors enhance dopamine and norepinephrine release (Moghaddam et al., 1990; Krebs et al., 1991; Wang et al., 1991; Lehmann et al., 1992). Since the activation of postsynaptic NMDA receptors can enhance dopamine release via the retrograde action of nitric oxide (reviewed by Dawson and Snyder, 1993), it has been postulated that NMDA receptors are postsynaptic, exclusively. Presynaptic NMDA action may be mediated by metabotropic glutamate receptors or a newly identified presynaptic glutamate receptor with NMDA-like properties, called GR 33 (Smirnova et al., 1993). Nevertheless, the present study indicates that the NMDA-R1 subunit is located presynaptically as well. It is not likely that our antiserum recognizes GR33, since GR33 and the NMDA-R1 subunit share no sequence homology. The present results cannot differentiate between the possibilities that presynaptic NMDA-R1 operate as subunits of autoreceptors or heteroreceptors. However, since some of the terminals exhibiting NMDA-R 1 immunoreactivity occur immediately adjacent to other terminals with glutamatergic morphological characteristics (i.e., forming axospinous asymmetric junctions, as described above), these cellular profiles might even be considered as functionally "postsynaptic." Furthermore, since dendrites postsynaptic to these immunoreactive axons most often lack NMDA-R1 immunoreactivity, axonal NMDA-R 1 is likely to reflect heteroreceptors residing in nonglutamatergic axon terminals.

The marginal zone (future lamina 1) matures early and exhibits high densities of NMDA-Rl immunoreactivity

Light and electron microscopy both show that tissue ranging in age from PND 2 through PND 30 exhibits higher areal densities of labeled profiles in the superficial laminae than in the middle $(4 / 5)$ or the deep (6/6B) laminae. At each age, it is the superficial laminae that exhibits the most mature ultrastructural features. The "adult-like" neuropil can be characterized by the high density of synaptic junctions, the prevalence of spinous profiles, terminals containing large clusters of vesicles (Blue and Parnavelas, 1983a,b), and the existence of astrocytic profiles that interleave between dendrites and axons (Peters et al., 1991). The prevalence of labeled and unlabeled synaptic junctions in the superficial laminae might have been expected, since immunoreactivity for synapsin $I$, a presynaptic marker in adult neural tissue (De Camilli et al., 1983), also is intense in the marginal zone from prenatal to postnatal stages (Chun and Shatz, 1988). Conversely, the paucity of labeled and unlabeled synaptic junctions in the deep laminae also is congruent with Chun and Shatz's results (1988), since they showed only transient synapsin I-immunoreactivity in the future white matter. The present study shows that the occurrence of discrete NMDA-R1 immunoreactivity over postsynaptic densities of synapses is also associated with maturation. NMDA-R1 immunoreactivity along the plasma membrane of astrocytes is yet another characteristic that emerges with maturation.

\section{Neonatal features of NMDA-RI immunoreactivity}

Electron microscopy reveals a dramatic change in the NMDAR1 immunolabeling pattern during the first few postnatal weeks. Most notably, NMDA-R1 immunoreactivity occurs diffusely along the plasma membrane of large-caliber dendrites. At the earliest ages examined, most of the immunoreactive dendrites 
are of large caliber and sparsely decorated by spines or synaptic junctions. It is possible that we fail to recognize axonal processes juxtaposed to dendrites, because axonal growth cones lack morphological features that allow for their definitive identification. However, some intensely immunoreactive dendritic plasma membranes have been observed to form direct contacts with neuronal somata; these certainly are not contacted by axonal processes or axonal growth cones. We were surprised to find that such immature dendrites already express NMDA-R1 immunoreactivity. Recent studies have shown that newly born migrating ncuronal perikarya already express functional NMDA receptors (Komuro and Rakic, 1993). This observation suggests that the insertion of NMDA receptors into the plasma membrane or the transport of them from the cell body to the dendritic trunks does not require axodendritic synaptic inputs or even contacts by axons. However, we cannot know whether the immunoreactive patches of dendritic membrane reflect sites vacated by axons that formed transient synapses or sites "waiting" for the arrival of axonal growth cones. Either way, the observation is concordant with that of Blue and Parnavelas (1983a), who noted that postsynaptic densities could be detected along immature dendritic membranes even in the absence of axons. Whether or not such immunoreactive patches of plasma membrane also exhibit thin (Miller and Peters, 1981), thick (Blue and Parnavelas, 1983a), or intermediate postsynaptic densities could not be discerned due to the accumulation of immunoperoxidase reaction product that obscures their details.

During ontogeny, dendritic NMDA-R 1 immunoreactivity becomes increasingly more localized to spinous postsynaptic densities. The labeled spines are, without exception, synaptically associated with axon terminals. Correspondingly, the frequency of nonsynaptic dendritic shaft labeling decreases during development. Somatic labeling, which is rare at any age, also decreases in frequency from PND 14 to PND 30. Together, these observations suggest that the localization of NMDA-R 1 subunits to distal dendrites and spine heads is under the influence of axonal inputs. NMDA-R 1 subunits may be pruned selectively along portions of the plasma membrane that fail to receive synaptic inputs. Alternatively, once inserted into the plasma membrane, newly synthesized NMDA-R1 subunits may diffuse laterally (within the plane of the plasma membrane) to sites receiving synaptic inputs. Our results cannot resolve between these possibilities, since we cannot relate the immunoreactive membrane patches' areal distribution or intensity of labeling to the number of receptor molecules localized there.

During ontogeny, NMDA-R1 immunoreactivity is first detectable in dendrites, followed by axons and finally astrocytic profiles. This temporal pattern may simply follow the developmental sequence of neurite maturation and astrocytic proliferation. Although radial glial cells are present prenatally and transform into astrocytes (Culican et al., 1990), Parnavelas et al. (1983) found mature astrocytes for the first time at $18 \mathrm{~d}$ postnatum. Moreover, Ling and Leblond (1973) reported that astrocyte number plateaus at around day 21 while neuronal number plateaus much earlier (reviewed by Rakic, 1981). Thus, it is not surprising that astrocytic immunolabeling is not detectable until the second week.

\section{Perikaryal labeling in neonatal tissue}

Nomarski differential interference contrast optics allow for the visualization of numerous perikarya that are intensely labeled within neonatal tissue. In addition, punctate labeling surround these neuronal cell bodies and their proximal dendrites. Electron microscopy indicates that at least some of the punctate immunolabeling over somata and dendrites reflects intracellular labeling along the postsynaptic membrane. Kageyama and Robertson (1993) have demonstrated recently that geniculocortical axons (which are glutamatergic) (Tsumoto, 1990) do form synapses with somata during early postnatal periods, while in adult cortical tissue, these and other glutamatergic axons rarely form axosomatic junctions (Garey and Powell, 1971; LeVay and Gilbert, 1976; Winfield and Powell, 1983; Somogyi et al., 1984; Aoki and Kabak, 1992). Since NMDA-R1 immunoreactivity along somatic plasma membrane is infrequent in adult tissue, it is likely that the axosomatic NMDA-R 1 immunoreactivity and glutamatergic axosomatic synaptic junctions both are transient.

The morphology of immunolabeled perikarya in neonatal tissue does not resemble that observed in adulthood. In the adult visual cortex, many of the labeled perikarya appear pyramidal, in that they exhibit horizontally extended dendrites that emerge from the base (basal dendrites) and a single dendrite that emerges from the apex of the cell body and extends toward pial surface (apical dendrite). The laminar distribution of immunoreactive perikarya also parallels that of pyramidal neurons in that they appear numerous and are of small diameter in the supragranular laminae, larger and spaced apart in lamina 5, and flattened in a single file within lamina 6B. According to developmental studics using Golgi-impregnated tissue, dendrites of immature pyramidal neurons also emerge from the apex and bases of the cell bodies, much as is seen in adulthood (Miller and Peters, 1981; Miller, 1984). Since the NMDA-R1-immunoreactive perikarya in neonatal tissue do not share these characteristics, these labeled perikarya may be of another class of neurons. Furthermore, since these nonpyramidal perikarya are not detectable in adult tissue, these may express NMDA-R $1 \mathrm{immu-}$ noreactivity only transiently. Alternatively, these perikarya may be destined for cell death during cortical maturation due to the prevalence of NMDA receptors that make them more prone to excitotoxicity (reviewed by Rothman and Olney, 1987).

The intensely labeled perikarya appear first in lamina 5 , followed by lamina 4 , then in laminae $2 / 3$, soon after the laminae have differentiated from the cortical plate. It is tempting to speculate that the intense labeling within these perikarya reflect some transient property that facilitates the pcrikarya's interaction with newly arriving glutamatergic afferents. Besides the most obvious possibility that the these perikarya express high levels of the NMDA-R 1 subunit, the NMDA-R 1 subunit may exhibit properties unique to newly generated neurons, such as decreased $\mathrm{Mg}^{2+}$ block (Kato and Yoshimura, 1993), decreased sensitivity to the open-channel blocker MK-801 (Kato, 1993), and decreased binding to various other ligands (Marti et al., 1993; Williams et al., 1993) together with elevated immunoreactivity to the employed antibody.

It is unlikely that the profuse punctate labeling in the neuropil, shown by electron microscopy to be dendritic and axonal, all emanate from these sparsely distributed perikarya. Furthermore, the regularly spaced bundles of immunoreactive processes in laminae 2/3 of PND 2 and PND 4 tissue probably are apical dendrites of pyramidal neurons, visualized previously by MAP2 immunocytochemistry (Peters and Sethares, 1991). We favor the interpretation that the antibody does recognize pyramidal neurons but that it favors recognition of NMDA-R 1 subunits in dendrites and axons over cell bodies. Another NMDA-R1 
antiserum has been shown to yield prominent staining of pyramidal perikarya in neonatal cerebral cortex (Vetter et al., 1993), thus supporting our view that pyramidal neurons do express NMDA-R 1 subunits.

\section{Ontogenic changes in the laminar distribution of labeled synapses}

NMDA receptors may play central roles in activity-dependent reorganization of synapses in the frog tectum (Schmidt, 1990; Udin and Scherer, 1990). During development, NMDA receptors are involved in the stabilization of synapses in the cat visual cortex (Kleinschmidt et al., 1987; Bear et al., 1990), cat visual thalamus (Hahm et al., 1991), and frog visual tectum (Cline et al., 1987). Whether or not NMDA receptors in the rat visual cortex play any role in the stabilization of developing synapses is not yet known. Nevertheless, we have shown that the frequency of NMDA-R1-immunoreactive synapses in the middle laminae peaks at an age when the geniculocortical axons' arborization (into laminae 4 and lower 3 ) nears completion (end of second postnatal week) (Kageyama and Robertson, 1993). This observation suggests that NMDA-R 1 subunits may be most abundant in the lamina where geniculocortical afferents reside and at an age ( PND 14) when geniculocortical synaptogenesis is most active.

In the superficial laminae, the density of NMDA-R1-immunolabeled synapses continues to rise toward adulthood (PND 30 ), even though the density of synapses, labeled and unlabeled, declines sharply from PND 18 to PND 30. The drop in synapse density probably reflects expansion of neuropil volume. If so, then the rise in the density of NMDA-R 1-immunolabeled synapses may reflect the insertion of NMDA-R 1 subunits into previously unlabeled synapses. Corticocortical synaptic plasticity in the superficial laminae of adult rat visual cortex may be dependent on NMDA receptors (Kirkwood et al., 1993). Thus, these NMDA-R1 subunits that are inserted late in ontogeny may participate in life-long plasticity rather than developmental plasticity. "Nonspecific" thalamic nuclei also innervate the superficial laminae (Herkenham, 1980; Glenn et al., 1982; reviewed by Jones, 1985). It would be interesting to learn whether NMDA receptors participate in the plasticity of "nonspecific" thalamocortical synapses.

\section{References}

Aoki C, Kabak S (1992) Cholinergic terminals in the cat visual cortex: ultrastructural basis for interaction with glutamate-immunoreactive neurons and other cells. Vis Neurosci 8:177-191.

Ascher P, Nowak L (1987) Electrophysiological studies of NMDA receptors. Trends Neurosci 7:284-288.

Bear MF, Kleinschmidt A, Gu Q, Singer W (1990) Disruption of experience-dependent synaptic modifications in striate cortex by infusion of an NMDA receptor antagonist. J Neurosci 10:909-925.

Bekkers J, Stevens CF (1989) NMDA and non-NMDA receptors are co-localized at individual excitatory synapses in cultured rat hippocampus. Nature 341:230-233.

Blue ME, Parnavelas JG (1983a) The formation and maturation of synapses in the visual cortex of the rat. I. Qualitative analysis. J Neurocytol 12:599-616.

Blue ME, Parnavelas JG (1983b) The formation and maturation of synapses in the visual cortex of the rat. II. Quantitative analysis. J Neurocytol 12:697-712.

Bustos G, Abarca J, Forray MI, Gysling K, Bradberry CW, Roth RH (1992) Regulation of excitatory amino acid release by $N$-methyl-Daspartate receptors in rat striatum: in vivo microdialysis studies. Brain Res 585:105-115

Chan J, Aoki C, Pickel VM (1990) Optimization of differential immunogold-silver and peroxidase labeling with maintenance of ultra- structure in brain sections before plastic embedding. J Neurosci Methods 33:113-127.

Chun JM, Shatz CJ (1988) Redistribution of synaptic vesicle antigens is correlated with the disappearance of a transient synaptic zone in the developing cerebral cortex. Neuron 1:297-310.

Cline HT, Debski EA, Constantine-Paton M (1987) N-methyl-D-aspartate receptor antagonist desegregates eye specific stripes. Proc Natl Acad Sci USA 84:4342-4345.

Culican SM, Baumrind NL, Yamamoto M, Pearlman AL (1990) Cortical radial glia: identification in tissue culture and evidence for their transformation to astrocytes. J Neurosci 10:684-692.

Cynader M, Mitchell DE (1980) Prolonged sensitivity to monocular deprivation in dark-reared cats. I Neurophysiol 43:1026-1040.

Dawson TM, Snyder SH (1993) Gases as biological messengers: nitric oxide and carbon monoxide in the brain. $J$ Neurosci, in press.

DeCamilli P, Harris SM, Huttner WB, Greengard P (1983) Synapsin I (protein I), a nerve terminal-specific phosphoprotein. II. Its specific association with synaptic vesicles demonstrated by immunocytochemistry in agarose-embedded synaptosomes. J Cell Biol 96:13551373.

Fox K, Daw NW (1993) Do NMDA receptors have a critical function in visual cortical plasticity? Trends Neurosci 16:116-122.

Fox K, Sato H, Daw N (1989) The location and function of NMDA receptors in cat and kitten visual cortex. J Neurosci 9:2443-2454.

Fox K, Daw N, Sato H, Czepita D (1991) Dark-rearing delays the loss of NMDA-receptor function in kitten visual cortex. Nature 350:342344.

Garey LJ, Powell TPS (1971) An experimental study of the termination of the lateral geniculo-cortical pathway in the cat and monkey. Proc R Soc Lond [Biol] 179:41-63.

Glenn LL, Hada J, Roy JP, Deschenes M, Steriade M (1982) Anterograde tracer and field potential analysis of the neocortical layer I projection from nucleus ventralis medialis of the thalamus in cat. Neuroscience 7:1861-1878.

Gray EG (1959) Axo-somatic and axo-dendritic synapses of the cerebral cortex. J Anat 93:420-433.

Hagihara K, Tsumoto T, Sato H, Hata Y (1988) Actions of excitatory amino acid antagonists on geniculo-cortical transmission in the cat's visual cortex. Exp Brain Res 69:407-416.

Hahm JO, Langdon RB, Sur M (1991) Disruption of retinogeniculate afferent segregation by antagonists to NMDA receptors. Nature 351 $568-570$.

Herkenham M (1980) Laminar organization of thalamic projections to rat neocortex. Science 207:532-534.

Herrera D, Cuello AC (1992) MK-801 affects the potassium-induced increase of glial fibrillary acidic protein immunoreactivity in rat brain. Brain Res 598:286-293.

Hirsch DB, Steiner JP, Dawson TM, Mammen A, Hayek E, Snyder SH (1993) Neurotransmitter release regulated by nitric oxide in PC 12 cells and brain synaptosomes. Curr Biol, in press.

Ishii T, Moriyoshi K, Sugihara H, Sakurada K, Kadotani H, Yokoi M, Akazawa C, Shigemoto R, Mizuno N, Masu M (1993) Molecular characterization of the family of the $N$-methyl-D-aspartate receptor subunits. J Biol Chem 268:2836-2843.

Jones EG (1985) The thalamus, pp 94-100. New York: Plenum.

Kageyama GH, Robertson RT (1993) Development of geniculocortical projections to visual cortex in rat: evidence for early ingrowth and synaptogenesis. J Comp Neurol 335:123-148.

Kato $\mathrm{N}$, Yoshimura H (1993) Reduced $\mathrm{Mg}^{2+}$ block of $N$-methyl-Daspartate receptor-mediated synaptic potentials in developing visual cortex. Proc Natl Acad Sci USA 90:7114-7118.

King JC, Lechan RM, Kuigel G, Anthony ELP (1983) Acrolein: a fixative for immunocytochemical localization of peptides in the central nervous system. J Histochem Cytochem 31:62-68.

Kirchhoff R, Blümcke I, Celio MR, Kettenmann H (1993)Patch-clamp analysis of glial cells in brain slices of murine neocortex. Soc Ncurosci Abstr 19:686.

Kirkwood A, Dudek S, Gold JT, Aizenman CD, Bear MF (1993) Common forms of synaptic plasticity in the hippocampus and neocortex in vitro. Science 260:1518-1521.

Kleinschmidt A, Bear MF, Singer W (1987) Blockade of "NMDA" receptors disrupts experience-dependent plasticity of kitten striate cortex. Science 238:355-358.

Komuro H, Rakic P (1993) Modulation of neuronal migration by NMDA receptors. Science 260:95-97. 
Krebs MO, Desce JM, Kemel ML, Gauchy C, Godeheu G, Cheramy A, Glowinski J (1991) Glutamatergic control of dopamine release in the rat striatum: evidence for presynaptic $N$-methyl-D-aspartate receptors on dopaminergic nerve terminals. J Neurochem 56:81-85.

Kutsuwada T, Kashiwabuchi N, Mori H, Sakimura K, Kushiya E, Araki K, Meguro H, Masaki H, Kumanishi T, Arakawa M, Mishina M (1992) Molecular diversity of the NMDA receptor channel. Nature 358:36-41.

Lehmann J, Valentino R, Robine V (1992) Cortical norepinephrine release elicited in situ by $N$-methyl-D-aspartate (NMDA) receptor stimulation: a microdialysis study. Brain Res 599:171-174.

LeVay S, Gilbert CD (1976) Laminar patterns of geniculocortical projection in the cat. Brain Res 113:1-19.

Ling EA, Leblond CP (1973) Investigation of glial cells in semithin sections. II. Variations with age in the numbers of the various glial cell types in rat cortex and corpus callosum. J Comp Neurol 149:7382.

Luskin MB, Shatz CJ (1985) Studies of the earliest generated cells of the cat's visual cortex: cogeneration of subplate and marginal zones. J Neurosci 5:1062-1075.

MacDermott AB, Dale N (1987) Receptors, ion channels and synaptic potentials underlying the integrative actions of excitatory amino acids. Trends Neurosci 7:280-284.

Maragos WF, Penney JB, Young AB (1988) Anatomic correlation of NMDA and ${ }^{3} \mathrm{H}$-TCP-labeled receptors in rat brain. J Neurosci 8:493501.

Marti T, Benke D, Mertens S, Heckendorn R, Pozza M, Allgeier H, Angst C, Laurie D, Seeburg P, Mohler H (1993) Molecular distinction of three $N$-methyl-D-aspartate-receptor subtypes in situ and developmental receptor maturation demonstrated with the photoaffinity ligand ${ }^{125}$ I-labeled CGP 55802A. Proc Natl Acad Sci USA 90:8434 8438.

Martin D, Bustos GA, Bowe MA, Bray SD, Nadler JV (1991) Autoreceptor regulation of glutamate and aspartate release from slices of the hippocampal CA1 area. J Neurochem 56:1647-1655.

Meguro H, Mori H, Araki K, Kushiya E, Kutsuwada T, Yamazaki M, Kumanishi T, Arakawa M, Sakimura K, Mishina M (1992) Functional characterization of a heteromeric NMDA receptor channel expressed from cloned cDNAs. Nature 357:70-74.

Miller M (1981) Maturation of rat visual cortex. I. A quantitative study of Golgi-impregnated pyramidal neurons. J Neurocytol 10:859_ 878.

Miller MW (1984) Development of projection and local circuit neurons in neocortex. In: Cerebral cortex, Vol 7, Development and maturation of cerebral cortex (Peters A, Jones EG, eds), pp 133-175. New York: Plenum.

Miller M, Peters A (1981) Maturation of rat visual cortex. II. A combined Golgi-electron microscope study of pyramidal neurons. J Comp Neurol 203:555-573.

Moghaddam B, Gruen RJ, Roth RH, Bunney BS, Adams RN (1990) Effect of L-glutamate on release of striatal dopamine: in vivo dialysis and electrochemical studies. Brain Res 518:55-60.

Monaghan DT, Cotman CW (1985) Distribution of $N$-methyl-D-aspartate-sensitive $\mathbf{L}-\left[{ }^{3} \mathrm{H}\right]$ glutamate-binding sites in rat brain. $\mathbf{J}$ Neurosci 5:2909-2919.

Monyer H, Sprengel R, Schoepfer R, Herb A, Higuchi M, Lomeli H, Burnashev N, Sakmann B, Seeberg PH (1992) Heteromeric NMDA receptors: molecular and functional distinction of subtypes. Science 256:1217-1221.

Moriyoshi K, Masu M, Ishii T, Shigemoto R, Mizuno N, Nakanishi S (1991) Molecular cloning and characterization of the rat NMDA receptor. Nature 354:31-37.

Morrison SF, Callaway J, Milner TA, Reis DJ (1989) Glutamate in the spinal sympathetic intermediolateral nucleus: localization by light and electron microscopy. Brain Res 503:5-15.

Müller T, Grosche J, Ohlemeyer C, Kettenmann H (1993) NMDAactivated currents in Bergmann glial cells. Neuroreport 4:671-674.

Nakanishi S (1992) Molecular diversity of glutamate receptors and implications for brain function. Science 258:597-603.

Nishigori A, Tsumoto T, Kimura F (1990) Contribution of quisqualate/kainate and NMDA receptors to excitatory synaptic transmission in the rat's visual cortex. Vis Neurosci 5:591-604.
Parnavelas JG, Luder R, Pollard SG, Sullivan K, Lieberman AR (1983) A qualitative and quantitative ultrastructural study of glial cells in the developing visual cortex of the rat. Philos Trans R Soc Lond [Biol] 301:55-84.

Peters A, Sethares C (1991) Organization of pyramidal neurons in area 17 of monkey visual cortex. J Comp Neurol 306:1-23.

Peters A, Palay SL, Webster H DeF (1991) The fine structure of the nervous system. New York: Oxford UP.

Rakic P (1977) Prenatal development of the visual system in rhesus monkey. Philos Trans R Soc Lond [Biol] 278:245-260.

Rakic P (1981) Developmental events leading to laminar and areal organization of the neocortex. In: The organization of the cerebral cortex (Schmitt FO, Worden FG, Adelman G, Dennis SG, eds), pp 3-28. Cambridge, MA: MIT Press.

Rice FL, Van der Loos H (1977) Development of barrels and barrel field in the somatosensory cortex of the mouse. J Comp Neurol 171 : $545-560$.

Rothman SM, Olney JW (1987) Excitotoxicity and the NMDA receptor. Trends Neurosci 10:302-305.

Sakurai SY, Cha J-HJ, Penny JB, Young AB (1991) Regional distribution and properties of $\left[{ }^{3} \mathrm{H}\right] \mathrm{MK}-801$ binding sites determined by quantitative autoradiography in rat brain. Neuroscience 2:533-543.

Schmidt JT (1990) Long-term potentiation and activity-dependent retinotopic sharpening in the regenerating retinotectal projection of goldfish: common sensitive period and sensitivity to NMDA blockers. J Neurosci 10:233-246.

Shirokawa T, Nishigori A, Kimura F, Tsumoto T (1989) Actions of excitatory amino acid antagonists on synaptic potentials of layer II/ III neurons of the cat's visual cortex. Exp Brain Res 78:489-500.

Smirnova T, Stinnakre J, Mallet J (1993) Characterization of a presynaptic glutamate receptor. Science 262:430-433.

Somogyi P, Halasy K, Somogyi J, Storm-Mathisen J, Ottersen OP (1986) Quantification of immunogold labelling reveals enrichment of glutamate in mossy and parallel fiber terminals in cat cerebellum. Neuroscience 19:1045-1050.

Sternberger LA (1986) Immunocytochemistry, 3d ed. New York: Wiley.

Streit $P$ (1984) Glutamate and aspartate as transmitter candidates for systems of the cerebral cortex. In: Cerebral cortex, Vol 2, Functional properties of cortical cells (Jones EG, Peters A, ed), pp 119-143. New York: Plenum Press.

Sugihara H, Moriyoshi K, Ishii T, Masu M, Nakanishi S (1992) Structures and properties of seven isoforms of the NMDA receptor generated by alternative splicing. Biochem Biophys Res Commun 185: 826-832.

Thomson AM (1986) A magnesium-sensitive post-synaptic potential in rat cerebral cortex resembles neuronal responses to $N$-methylaspartate. J Physiol (Lond) 370:531-549.

Tsumoto T (1990) Excitatory amino acid transmitters and their receptors in neural circuits of the cerebral cortex. Neurosci Res 9:79102.

Uchihori Y, Puro DG (1993) Glutamate as a neuron-to-glial signal for mitogenesis: role of glial $\mathrm{N}$-methyl-D-aspartate receptors. Brain Res 613:212-220.

Udin SB, Scherer WJ (1990) Restoration of the plasticity of binocular maps by NMDA after the critical period in Xenopus. Science 249 : 669-672.

Vetter DE, Brose N, IIeinemann SF (1993) Immunocytochemical localization of the NMDA R1 subunit in rat brain. Soc Neurosci Abstr 19:304.

Wang JKT, Andrews H, Thurkral V (1991) Presynaptic glutamate receptors regulate noradrenaline release from isolated nerve terminals. J Neurochem 58:204-211.

Williams K, Russel SL, Shen YM, Molinoff PB (1993) Developmental switch in the expression of NMDA receptors occurs in vivo and in vitro. Neuron 10:267-278.

Winfield DA, Powell TPS (1983) Laminar cell counts and geniculocortical boutons in area 17 of cat and monkey. Brain Res 277:223229. 